\title{
REVIEW
}

\section{Studies of Earthquake Energies in Taiwan: A Review}

\author{
Jeen-Hwa Wang * \\ Institute of Earth Sciences, Academia Sinica, Taipei, Taiwan, R.O.C.
}

Received 7 July 2015, revised 7 October 2015, accepted 13 October 2015

\begin{abstract}
This paper reviews studies on earthquake energies, seismic efficiency, radiation efficiency, scaled energy and energy-magnitude law conducted by Taiwan seismologists and foreigners who used seismic data from Taiwan to study these problems. Sufficient seismic and geodetic data permits energy measurements from the 20 September $1999 \mathrm{M}_{\mathrm{s}}$ 7.6 Chi-Chi earthquake and its larger-sized aftershocks. The results provide significant information on earthquake physics. The issues in this review paper include measures of these physical quantities and related theoretical or analytical studies of these physical quantities made by both Taiwan's seismologists and foreigners who used seismic data of Taiwan to study related problems.
\end{abstract}

Key words: Earthquake energies, Seismic efficiency, Radiation efficiency, Scaled energy, Energy-magnitude law

Citation: Wang, J. H., 2016: Studies of earthquake energies in Taiwan: A review. Terr. Atmos. Ocean. Sci., 27, 1-19, doi: 10.3319/TAO.2015.10.13.01(T)

\section{INTRODUCTION}

After an earthquake ruptures the frictional stress, $\sigma(t)$, which is a function of time and slip on a fault plane, decreases from an initial $\sigma_{\mathrm{o}}$ to a dynamic $\sigma_{\mathrm{d}}$, and finally becomes $\sigma_{\mathrm{f}}$ (see Fig. 1). In general $\sigma_{\mathrm{d}}$ is equal to or smaller than $\sigma_{\mathrm{f}}$ (Kanamori and Heaton 2000). $\mathrm{D}_{\max }$ is the maximum or total displacement. According to the slip- and rate-weakening frictional law, the frictional stress changes from $\sigma_{\mathrm{o}}$ to $\sigma_{\mathrm{d}}$ in a characteristic slip displacement, $\mathrm{D}_{\mathrm{c}}$ (Marone 1998; Wang 2002). The friction law that describes the frictional stress is complicated (cf. Ruina 1983; Marone 1998; Wang 2002). However, it can be approximated using a piece-wise linear function displayed in Fig. 1, which shows an example with $\sigma_{\mathrm{d}}=\sigma_{\mathrm{f}}$. The static stress drop $\Delta \sigma_{\mathrm{s}}=\sigma_{\mathrm{o}}-\sigma_{\mathrm{f}}$ and the dynamic stress drop $\Delta \sigma_{d}=\sigma_{o}-\sigma_{d}$ are usually used to specify the change in stresses on a fault.

The strain energy, $\Delta \mathrm{E}$, which results from tectonic loading, can release during an earthquake. The strain energy, $\Delta \mathrm{E}$, per unit area can be approximated using the area of a trapezoid underneath the linearly decreasing stress versus slip function, i.e., the line segment AD in Fig. 1. The strain energy $\Delta \mathrm{E}$ is transferred into, at least, three parts (see Fig. 1):

\footnotetext{
* Corresponding author

E-mail:jhwang@earth.sinica.edu.tw
}

the seismic radiation energy $\left(\mathrm{E}_{\mathrm{s}}\right)$, fracture energy $\left(\mathrm{E}_{\mathrm{g}}\right)$, and frictional energy $\left(\mathrm{E}_{\mathrm{f}}\right)$, that is, $\Delta \mathrm{E}=\mathrm{E}_{\mathrm{s}}+\mathrm{E}_{\mathrm{g}}+\mathrm{E}_{\mathrm{f}} . \mathrm{E}_{\mathrm{s}}$ is the energy radiated through seismic waves which leads to ground motions and can be detected by seismographs. $E_{\mathrm{g}}$ is the energy used to extend the fault plane and cannot be measured directly from seismograms. $E_{f}$, which results from the dynamic friction stress, can generate heat. Because of incomplete data there are high uncertainties in measuring these energies, especially for $\mathrm{E}_{\mathrm{f}}$.

Two physical quantities, i.e., seismic efficiency and radiation efficiency, are defined directly from the four types of earthquake energies to represent source properties. The seismic efficiency, $\eta$, which is defined as the ratio of $E_{s}$ to $\Delta \mathrm{E}$, i.e., $\eta=\mathrm{E}_{\mathrm{s}} / \Delta \mathrm{E}$, has been long taken to present the level of seismic-wave radiation generated from an earthquake source. Kanamori and Heaton (2000) defined the radiation efficiency, $\eta_{R}$, as $\eta_{R}=E_{s} /\left(E_{s}+E_{g}\right)$. This parameter can be evaluated directly from seismograms. Venkataraman and Kanamori (2004) observed $\eta_{R}=0.25-1$ for most earthquakes. Taking the seismic moment $\left(\mathrm{M}_{\mathrm{o}}\right)$ into account, Kanamori (1977) defined the scaled energy as the ratio of seismic radiation energy to the seismic moment, i.e., $e_{R}=E_{s} / M_{0}$. It can be written as $\left(2 \Delta \sigma_{d}-\Delta \sigma_{s}\right) / 2$ (Kanamori and Heaton 2000). Gutenberg and Richter (1956) related the seismic radiation energy to earthquake magnitude: 
$\log \left(\mathrm{E}_{\mathrm{s}}\right)=11.8+1.5 \mathrm{M}_{\mathrm{s}}\left(\mathrm{E}_{\mathrm{s}}\right.$ in ergs $)$. This equation is the socalled Gutenberg-Richter's energy-magnitude law (abbreviated as the GR law hereafter), which is an important earthquake source scaling law.

Taiwan is located at the juncture of the Eurasian plate and the Philippine Sea plate (Tsai et al. 1977; Wu 1978; Lin 2002). The Philippine Sea plate has been moving northwestward at a speed of $\sim 80 \mathrm{~mm}$ year $^{-1}$ (Yu et al. 1997) to collide with the Eurasian plate. The Okinawa Trough extends southwestward to approach Taiwan (Eguchi and Uyeda 1983). Active orogeny due to the collision of these two plates causes complex geological features and high seismicity in the region (from $119-123^{\circ} \mathrm{E}$ and $21-26^{\circ} \mathrm{N}$ ). The complex tectonics in the region results in a non-uniform spatial earthquake distribution (Wang 1988, 1998; Wang and Shin 1998). High and heterogeneous seismicity in Taiwan makes the region serve as one of the best natural laboratories for seismological studies. Hence, seismicity studies have been conducted in Taiwan for more than one century (Wang 1998; Wang and Shin 1998). There are numerous types of seismic stations in the region (Wang 1989; Shin and Chang 2005). This makes studies of earthquake energies possible. On 20 September 1999 the $M_{\mathrm{s}}$ 7.6 Chi-Chi earthquake ruptured the Chelungpu fault, which is a 100-km-long and east-dipping thrust fault, with a dip angle of $30^{\circ}$, in Central Taiwan (Ma et al. 1999; Shin and Teng 2001). The earthquake and its large aftershocks caused severe damage in Taiwan (Wang et al. 2005). A large number of seismological, geophysical and geological data were collected for earth scientists to study. From these data fruitful research results for the earthquake sequence and related problems have been made by earth scientists (Wang 2006b, 2010; Wang et al. 2005). The main shock energies and its larger-sized aftershocks were measured (Wang 2006a, 2010). The results provide significant information on earthquake physics.

This paper reviews the studies (including measures, methodologies, and theory) of earthquake energies, seismic efficiency, radiation efficiency, scaled energy, and energymagnitude law made by Taiwan seismologists and foreigners who applied Taiwan seismic data to study earthquake energies. The main issues include the measures of these physical quantities for Taiwan earthquakes and the related theoretical or analytical studies of these physical quantities. To obtain completeness of this work, included also are the related studies for physical quantities in use done by the foreigners.

\section{DESCRIPTION OF ENERGIES OF EARTHQUAKES}

\subsection{Strain Energy}

The strain energy exerted by geotectonics and released during an earthquake can be written as (cf. Knopoff 1958):

$\Delta \mathrm{E}=\int \mathrm{u}_{\mathrm{i}}\left(\sigma_{\mathrm{oij}}+\sigma_{\mathrm{fij}}\right) \nu_{\mathrm{j}} \mathrm{dS}$

where $\mathrm{u}_{\mathrm{i}}$ is the slip along the i-th axis, $v_{\mathrm{j}}$ is the unit vector normal to the fault plane and along the $\mathrm{j}$-th axis, and $\sigma_{\mathrm{oij}}$ and $\sigma_{\text {fij }}$ are, respectively, the initial (denoted by "o") and final (shown by "f") stress tensors, and S and dS are, respectively, the area and the unit area on the fault plane. Under some assumptions (Kostrov 1974; Dahlen 1977), an approximated formula of strain energy can be written as

$\Delta \mathrm{E}=\left(\sigma_{\mathrm{o}}+\sigma_{\mathrm{f}}\right)_{\mathrm{ave}} \overline{\mathrm{u}} \mathrm{S} / 2$

where $\overline{\mathrm{u}}$ is the displacement on the fault plane and $(\ldots)_{\text {ave }}$ denotes the average quantities inside the parenthesis and $\mathrm{S}$ is the ruptured area. The values $\sigma_{\mathrm{o}}$ and $\sigma_{\mathrm{f}}$ cannot be determined just from seismological observations. When crustal deformation data are available, we can evaluate $\Delta \mathrm{E}$.

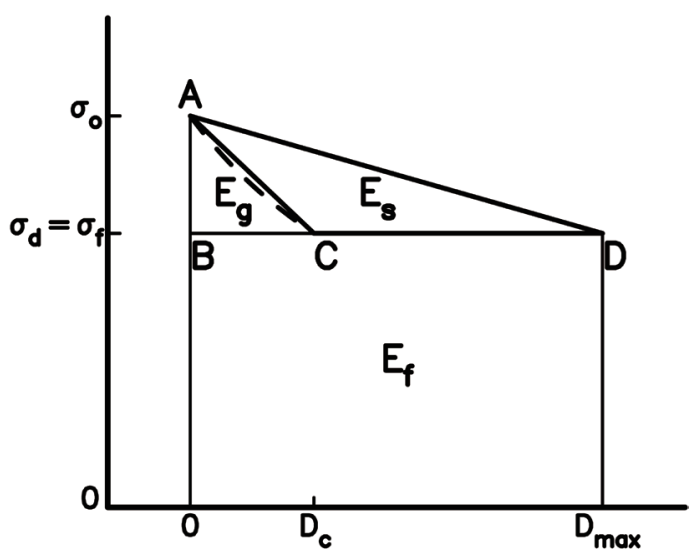

Fig. 1. The stress-slip function: lines $\mathrm{AC}$ and CD represent slip-weakening friction, $\mathrm{D}_{\mathrm{c}}=$ the characteristic slip displacement, $\mathrm{D}_{\max }=$ the maximum slip, $\sigma_{\mathrm{o}}=$ initial stress (or static frictional stress), $\sigma_{\mathrm{d}}=$ dynamic frictional stress, and $\sigma_{\mathrm{f}}=$ final stress. The strain energy, $\Delta \mathrm{E}$, per unit area is the area of a trapezoid below line $\mathrm{AD}, \mathrm{E}_{\mathrm{s}}=$ seismic radiation energy, $\mathrm{E}_{\mathrm{g}}=$ fracture energy, and $\mathrm{E}_{\mathrm{f}}=$ frictional energy . 
Wang (2004) proposed a method to measure $\Delta \mathrm{E}$ of an earthquake from the slip distribution of an earthquake source inversed from crustal deformation data. In his method the rotation components are excluded due to small values. $\mathrm{He}$ wrote $\Delta \mathrm{E}$ as $\Delta \mathrm{E}=\Delta \mathrm{E}_{\mathrm{L}}+\Delta \mathrm{E}_{\mathrm{W}}$, where $\Delta \mathrm{E}_{\mathrm{L}}$ and $\Delta \mathrm{E}_{\mathrm{W}}$ denote the strained energies along the fault-striking $(\mathrm{L})$ direction and the fault-dipping (W) one, respectively. From Eq. (2), $\Delta \mathrm{E}_{\mathrm{L}}=\left[\left(\sigma_{\mathrm{oL}}+\sigma_{\mathrm{fL}}\right) / 2\right] \mathrm{u}_{\mathrm{L}} \mathrm{A}$ and $\Delta \mathrm{E}_{\mathrm{W}}=\left[\left(\sigma_{\mathrm{oW}}+\sigma_{\mathrm{fw}}\right) / 2\right] \mathrm{u}_{\mathrm{W}} \mathrm{S}$, where $\mathrm{u}_{\mathrm{L}}$ and $\mathrm{u}_{\mathrm{W}}$ are the average displacements along the $\mathrm{L}$ and W-directions, respectively. Define $\sigma_{\mathrm{L}}=\left(\sigma_{\mathrm{oL}}+\sigma_{\mathrm{fL}}\right) / 2$ and $\sigma_{\mathrm{W}}=\left(\sigma_{\mathrm{oW}}+\sigma_{\mathrm{fW}}\right) / 2$, thus leading to $\Delta \mathrm{E}_{\mathrm{L}}=\sigma_{\mathrm{L}} \mathrm{u}_{\mathrm{L}} \mathrm{S}$ and $\Delta \mathrm{E}_{\mathrm{W}}=$ $\sigma_{\mathrm{W}} \mathrm{u}_{\mathrm{W}} \mathrm{S}$. Since $\sigma_{\mathrm{L}} \approx \mu\left(\mathrm{u}_{\mathrm{L}} / \mathrm{L}\right)$ and $\sigma_{\mathrm{W}} \approx \mu\left(\mathrm{u}_{\mathrm{W}} / \mathrm{W}\right)$, where $\mu$ is the rigidity of the fault zone, $\Delta \mathrm{E}_{\mathrm{L}}=\mu\left(\mathrm{u}_{\mathrm{L}} / \mathrm{L}\right) \mathrm{u}_{\mathrm{L}} \mathrm{S}, \Delta \mathrm{E}_{\mathrm{W}}=\mu\left(\mathrm{u}_{\mathrm{W}} / \mathrm{W}\right)$ $\mathrm{u}_{\mathrm{W}} \mathrm{S}$, and $\Delta \mathrm{E}=\mu\left[\left(\mathrm{u}_{\mathrm{L}} / \mathrm{L}\right) \mathrm{u}_{\mathrm{L}}+\mu\left(\mathrm{u}_{\mathrm{W}} / \mathrm{W}\right) \mathrm{u}_{\mathrm{W}}\right] \mathrm{S}$. The errors due to approximation are $\mathrm{L}\left(\mathrm{d}^{2} \sigma_{\mathrm{L}} / \mathrm{dx}^{2}\right)$ for $\sigma_{\mathrm{L}}$ and $\mathrm{W}\left(\mathrm{d}^{2} \sigma_{\mathrm{W}} / \mathrm{dy}^{2}\right)$ for $\sigma_{\mathrm{W}}$. The values of $\mathrm{d}^{2} \sigma_{\mathrm{L}} / \mathrm{dx}^{2}$ and $\mathrm{d}^{2} \sigma_{\mathrm{W}} / \mathrm{dy}^{2}$ are unknown. However, it sounds reasonable to assume $\mathrm{d}^{2} \sigma_{\mathrm{L}} / \mathrm{dx}^{2} \approx 0$ and $\mathrm{d}^{2} \sigma_{\mathrm{w}} / \mathrm{dy}^{2} \approx 0$, when the variation in the stress field is low within the space domain in use. In practice, the stress field is considered to be constant inside a grid through the inversion procedure. This would lead to small errors. Except for the areas with abnormally large changes in displacements, the variation in slip on the fault is smooth, and thus, the higherorder derivatives of deformations would be small. In the practical inversion procedure the displacement on a grid is set to be a constant. This makes the higher-order derivatives of deformation be zero. Therefore, the difference between the estimated and real strain energies caused by excluding the two components should be small.

\subsection{Seismic Radiation Energy}

The seismic radiation energy, $\mathrm{E}_{\mathrm{s}}$, is the energy radiated from the earthquake source through seismic waves. Rivera and Kanamori (2005) proposed a representation theory to describe the seismic radiation energy. In their theory, the strain energy and $E_{s}$ are written as a function of the displacements and stresses in the fault zone. However, a simplified form is described below In Fig. 1, $\mathrm{E}_{\mathrm{s}}$ per unit area is the quantity inside triangle ACD. Assuming that during sliding the friction stress is almost constant acted on by dynamic friction, $\sigma_{\mathrm{d}}$, with a dynamic stress drop $\Delta \sigma_{\mathrm{d}}$, the seismic energy is $\mathrm{E}_{\mathrm{s}}=\Delta \mathrm{E}-\mathrm{E}_{\mathrm{g}}-\mathrm{E}_{\mathrm{f}}=\left(\sigma_{\mathrm{o}}+\sigma_{\mathrm{f}}\right) \overline{\mathrm{u}} \mathrm{S} / 2-\overline{\mathrm{u}} \mathrm{S}-2 \mathrm{GS}$, where $\mathrm{G}$ is the fracture energy density as defined below. Making the additional assumption that the surface fracture energy is negligible, we obtain the simple expression

$\mathrm{E}_{\mathrm{s}}=\mathrm{M}_{\mathrm{o}}\left(2 \Delta \sigma_{\mathrm{d}}-\Delta \sigma_{\mathrm{s}}\right) / 2 \mu$

(cf. Kanamori and Heaton 2000; Kanamori and Brodsky 2004), where $M_{o}, \Delta \sigma_{d}$, and $\Delta \sigma_{s}$ are, respectively, the seismic moment, dynamic stress drop and static stress drop. From Eq. (3) it is clear that the seismic radiation energy contains only information concerning the stress change during the earthquake rupture, and no information concerning the total source area stress (cf. Scholz 1990). From the previous models $E_{\mathrm{s}}$ can be evaluated from the displacements and stresses on the fault plane (Boatwright 1980; Ide 2002; Favreau and Archuleta 2003).

On the other hand, $E_{\mathrm{s}}$ can be measured from seismic waves. Galitzin (1915) first measured the $\mathrm{E}_{\mathrm{s}}$ value of the Pamir earthquake of 18 February 1911 from far-field seismic waves. Jeffreys (1923) corrected the formula used by Galitzin (1915) to measure $\mathrm{E}_{\mathrm{s}}$. He calculated the total elastic wave energy in an earthquake spreading out spherically from a focus. Gutenberg and Richter (1942) suggested a simplified formula to calculate $\mathrm{E}_{\mathrm{s}}$. They considered that at the epicenter the radiated energy arrives principally in a series of $n$ equal sinusoidal waves of length $\lambda$, amplitude $A_{0}$, and period $T_{0}$. The kinetic energy per unit volume is $\rho\left(2 \pi \mathrm{A}_{\mathrm{o}} / \mathrm{T}_{\mathrm{o}}\right)^{1 / 2} / 4$ where $\rho$ is the density of the source area and the quantity in parentheses is the maximum velocity of a particle, and one factor $1 / 2$ is due to averaging $\sin ^{2}\left(2 \pi t / T_{0}\right)$ over a period. If the wave velocity $\mathrm{v}$ is constant the mean energy in a spherical shell of volume $4 \pi h^{2} n \lambda$ where $h$ is the linear distance from the source. Hence, putting $\mathrm{nT}_{\mathrm{o}}=\mathrm{t}_{\mathrm{o}}$ and $\lambda=\mathrm{vT}_{\mathrm{o}}$ leads to $\mathrm{n} \lambda=\mathrm{vt}_{\mathrm{o}}$ and $\mathrm{E}_{\mathrm{s}}=4 \pi^{3} \mathrm{~h}^{2} \mathrm{vt}_{\mathrm{o}} \rho\left(\mathrm{A}_{\mathrm{o}} / \mathrm{T}_{\mathrm{o}}\right)^{2}=$ $\mathrm{h}^{2} \mathrm{vt} \mathrm{o}_{\mathrm{o}} \rho\left(\mathrm{a}_{\mathrm{o}} \mathrm{T}_{\mathrm{o}}\right)^{2} / 4 \pi$, where $\mathrm{a}_{\mathrm{o}}$ is the acceleration, because of $\mathrm{A}_{\mathrm{o}}=\mathrm{a}_{\mathrm{o}} \mathrm{T}_{\mathrm{o}}{ }^{2} / 4 \pi^{2}$. In their calculations, they took $\mathrm{v}=3.4 \mathrm{~km} \mathrm{~s}^{-1}$ and $\rho=2.7 \mathrm{gm} \mathrm{cm}^{-3}$. Note that the two ways used by Jeffreys (1923) and Gutenberg and Richter (1942) were too simplified to accurately measure the $\mathrm{E}_{\mathrm{s}}$ value. Meanwhile, the corrections that are necessary to revise the measured value of $\mathrm{E}_{\mathrm{s}}$ as mentioned below were not made in their studies.

Currently the seismic radiation energy is commonly measured from either recorded velocity seismograms or the velocity waveforms performed from the displacement seismograms or accelerograms based on the following expression:

$E_{s}=S_{a} \rho \beta \int v^{2}(t) d t=2 S_{a} \rho \beta \int V^{2}(f) d f$

where $S_{a}=2 \pi r^{2}(r=$ hypocentral distance $), \rho=$ density, $\beta=S$-wave velocity, $v(t)=$ the velocity seismogram, and $V(f)=$ Fourier Transform of $v(t)$. Es can be measured from three kinds of waves: the P-, S-waves, and Rayleigh waves (Boatwright and Fletcher 1984; Choy and Boatwright 1995; Pérez-Campos and Beroza 2001). However, several factors can influence the measures of $E_{s}$. These factors include (1) instrumental response; (2) free surface amplification factor of 2; (3) seismic attenuation represented by the Q-value; (4) radiation pattern correction, i.e., $\mathrm{R}^{1 / 2}=(2 / 5)^{1 / 2}=0.63 ;(5) \mathrm{di}$ rectivity; (6) trapped-wave effect; (7) difference in the geological structures between the foot wall and hanging wall; (8) finite frequency bandwidth limitation effect (abbreviated the FFBL effect hereafter); and (9) site effect (especially for f $>3 \mathrm{~Hz}$ signals). Since the factors from (1) to (7) are less 
complicated and well-known, only the FFBL effect and site effect are described below.

\subsubsection{The Effect Due to Finite Frequency Bandwidth Limitation}

The source spectra of earthquakes are mainly controlled by the low-frequency spectral level $\left(\Omega_{\mathrm{o}}\right)$ and corner frequency $\left(f_{c}\right)($ Haskell 1966; Aki 1967; Brune 1970). When $\mathrm{f}>\mathrm{f}_{\mathrm{c}}$, the spectral amplitude decays in a power-law function like $\mathrm{f}^{-\alpha}$. The scaling exponents are -2 and -3 , respectively, referred to as the $\omega^{-2}(\omega=2 \pi f)$ and $\omega^{-3}$ source models. Huang and Wang (2002) observed that the scaling exponents of displacement spectra of the 1999 Chi-Chi, Taiwan, earthquake from the seismograms at nine near-fault stations increase from 1.63 - 3.04 from south to north. Hence, the two source models should be taken into account.

Let $\mathrm{d}(\mathrm{t})$ and $\mathrm{v}(\mathrm{t})$ be the source displacement and velocity, respectively. Their Fourier transforms are, respectively, $\mathrm{D}(\mathrm{f})$ and $\mathrm{V}(\mathrm{f})$. $\mathrm{D}(\mathrm{f})$ can be approximated by $\mathrm{D}_{2}(\mathrm{f})=\Omega_{\mathrm{o}} /\left[1+\left(\mathrm{f} / \mathrm{f}_{\mathrm{c}}\right)^{2}\right]$ for the $\omega^{-2}$ model and $\mathrm{D}_{3}(\mathrm{f})=\Omega_{\mathrm{o}} /[1+$ $\left.\left(\mathrm{f} / \mathrm{f}_{\mathrm{c}}\right)^{2}\right]^{3 / 2}$ for the $\omega^{-3}$ one (cf. Beresnev and Atkinson 1997). Hence, the approximations of V(f) are, respectively:

$\mathrm{V}_{2}(\mathrm{f})=2 \pi \mathrm{f} \Omega_{\mathrm{o}} /\left[1+\left(\mathrm{f} / \mathrm{f}_{\mathrm{c}}\right)^{2}\right]$

for the $\omega^{-2}$ model; and

$\mathrm{V}_{3}(\mathrm{f})=2 \pi \mathrm{f} \Omega_{\mathrm{o}} /\left[1+\left(\mathrm{f} / \mathrm{f}_{\mathrm{c}}\right)^{2}\right]^{3 / 2}$

for the $\omega^{-3}$ model. Figure 2 shows the log-log plots of the normalized, simplified velocity spectra, $V(f)$ versus $f$. Since $\mathrm{V}_{2}(\mathrm{f}) \sim \mathrm{f}^{1}$ and $\mathrm{V}_{3}(\mathrm{f}) \sim \mathrm{f}^{1}$ as $\mathrm{f}<<\mathrm{f}_{\mathrm{c}}$ and $\mathrm{V}_{2}(\mathrm{f}) \sim \mathrm{f}^{-1}$ and $\mathrm{V}_{3}(\mathrm{f}) \sim \mathrm{f}^{-2}$ as $f>f_{c}$, Eqs. (5) - (6) can be approximated individually by a piece-wise linear function as shown in Fig. 2. In the figure, the dashed and dotted lines, respectively, represent the $\omega^{-1}$ and $\omega^{-2}$ source velocity models.

In principle, the first integral in Eq. (4) is calculated from $-\infty$ to $+\infty$ in the time domain and the second one from 0 to $+\infty$ in the frequency domain. Define

$I_{V}=\int v^{2}(t) d t=2 \int V^{2}(f) d f$

This gives $\mathrm{E}_{\mathrm{s}}=4 \pi \rho \beta \mathrm{I}_{\mathrm{v}}$.

Ide and Beroza (2001) first pointed out the effect on measuring seismic radiation energy due to the FFBL, which is caused by windowing the source spectra in a frequency band from $f_{1}$ to $f_{u}$ as displayed in Fig. 2. The FFBL effect would change the source spectra in use, thus influencing the measured value of $\mathrm{E}_{\mathrm{s}}$.

Wang (2004) derived the formulas to present the FFBL effect based on the two models. In the followings, a sub- script is taken ' 0 ' to denote a quantity obtained through integration from $-\infty$ and $+\infty \mathrm{sec}$ in the time domain or from 0 to $+\infty \mathrm{Hz}$ in the frequency domain. Inserting Eqs. (5) and (6), respectively, into Eq. (7), with $\mathrm{f}_{1}=0$ and $\mathrm{f}_{\mathrm{u}}=\infty$, leads to $\mathrm{I}_{\mathrm{V} 20}=\Omega_{\mathrm{o}}{ }^{2}\left(2 \pi \mathrm{f}_{\mathrm{c}}\right)^{3} / 4$ for the $\omega^{-2}$ model; and $\mathrm{I}_{\mathrm{V} 30}=\Omega_{\mathrm{o}}{ }^{2}\left(2 \pi \mathrm{f}_{\mathrm{c}}\right)^{3} / 16$ for the $\omega^{-3}$ model. This gives $\mathrm{I}_{\mathrm{V} 20}=4 \mathrm{I}_{\mathrm{V} 30}$. Inserting Eqs. (5) and (6), respectively, into Eq. (7) and integrating from $f_{1}$ to $\mathrm{f}_{\mathrm{u}}$, lead to, respectively, $\mathrm{I}_{\mathrm{V} 2}=\mathrm{I}_{\mathrm{V} 20} \mathrm{~F}_{\mathrm{V} 2}$, and $\mathrm{I}_{\mathrm{V} 3}=\mathrm{I}_{\mathrm{V} 30} \mathrm{~F}_{\mathrm{V} 3}$, where $\mathrm{F}_{\mathrm{V} 2}=(2 / \pi)\left\{-\left(\mathrm{f}_{\mathrm{u}} / \mathrm{f}_{\mathrm{c}}\right) /\left[1+\left(\mathrm{f}_{\mathrm{u}} / \mathrm{f}_{\mathrm{c}}\right)^{2}\right]+\left(\mathrm{f}_{\mathrm{f}} / \mathrm{f}_{\mathrm{c}}\right) /\left[1+\left(\mathrm{f}_{1} / \mathrm{f}_{\mathrm{c}}\right)^{2}\right]\right.$ $\left.+\tan ^{-1}\left(\mathrm{f}_{\mathrm{u}} / \mathrm{f}_{\mathrm{c}}\right)-\tan ^{-1}\left(\mathrm{f}_{\mathrm{l}} / \mathrm{f}_{\mathrm{c}}\right)\right\}$ for the $\omega^{-2}$ model; $\mathrm{F}_{\mathrm{V} 3}=(4 / \pi)$ $\left\{-\left(\mathrm{f}_{\mathrm{u}} / \mathrm{f}_{\mathrm{c}}\right) /\left[1+\left(\mathrm{f}_{\mathrm{u}} / \mathrm{f}_{\mathrm{c}}\right)^{2}\right]^{2}+\left(\mathrm{f}_{\mathrm{u}} / \mathrm{f}_{\mathrm{c}}\right) / 2\left[1+\left(\mathrm{f}_{\mathrm{u}} / \mathrm{f}_{\mathrm{c}}\right)^{2}\right]+\tan ^{-1}\left(\mathrm{f}_{\mathrm{u}} / \mathrm{f}_{\mathrm{c}}\right) / 2+\right.$ $\left.\left(\mathrm{f}_{l} / \mathrm{f}_{\mathrm{c}}\right) /\left[1+\left(\mathrm{f}_{l} / \mathrm{f}_{\mathrm{c}}\right)^{2}\right]^{2}-\left(\mathrm{f}_{l} / \mathrm{f}_{\mathrm{c}}\right) / 2\left[1+\left(\mathrm{f}_{l} / \mathrm{f}_{\mathrm{c}}\right)^{2}\right]-\tan ^{-1}\left(\mathrm{f}_{l} / \mathrm{f}_{\mathrm{c}}\right) / 2\right\}$ for the $\omega^{-3}$ model. It is noted that when $\mathrm{f}_{1}=0$ and $\mathrm{f}_{\mathrm{u}} \rightarrow \infty, \mathrm{F}_{\mathrm{V} 2}=1$ and $\mathrm{F}_{\mathrm{V} 3}=1$, and, thus, $\mathrm{I}_{\mathrm{V} 2}=\mathrm{I}_{\mathrm{V} 20}$ and $\mathrm{I}_{\mathrm{V} 2}=\mathrm{I}_{\mathrm{V} 30}$.

Let $\mathrm{E}_{\mathrm{so}}$ and $\mathrm{E}_{\mathrm{s}}$ denote, respectively, the seismic radiation energy without and with, respectively, the FFBL effect. Hence, the energy ratio is $\mathrm{E}_{\mathrm{s} 2} / \mathrm{E}_{\mathrm{s} 0}=\mathrm{F}_{\mathrm{V} 2}$ for the $\omega^{-2}$ model and $\mathrm{E}_{\mathrm{s} 3} / \mathrm{E}_{\mathrm{s}}=\mathrm{F}_{\mathrm{V} 3}$ for the $\omega^{-3}$ model. Examples of the variations of $\mathrm{E}_{\mathrm{s}} / \mathrm{E}_{\mathrm{so}}$ with $\mathrm{f}_{\mathrm{l}} / \mathrm{f}_{\mathrm{c}}=0.05-0.95$ and $\mathrm{f}_{\mathrm{u}} / \mathrm{f}_{\mathrm{c}}=2$ to 20 , with a difference of 2, are shown, respectively, in Fig. 3 (for $\mathrm{E}_{\mathrm{s} 2} / \mathrm{E}_{\mathrm{so}}$ ) and Fig. 4 (for $\mathrm{E}_{\mathrm{s} 3} / \mathrm{E}_{\mathrm{so}}$ ), where the dotted line displays the energy ratio of 1 and also displayed are the maximum values for respective cases. Figures 3 and 4 express $\mathrm{E}_{\mathrm{s} 2} / \mathrm{E}_{\mathrm{so}}<1$, with a maximum of 0.937 , and $\mathrm{E}_{\mathrm{s} 3} / \mathrm{E}_{\mathrm{so}}<1$, with a maximum of 0.999. Obviously, the FFBL effect yields under-estimates of seismic radiation energy. $\mathrm{E}_{\mathrm{s} 2} / \mathrm{E}_{\mathrm{so}}$ and $\mathrm{E}_{\mathrm{s} 3} / \mathrm{E}_{\mathrm{s} 0}$ both decrease with increasing $\mathrm{f}_{1} / \mathrm{f}_{\mathrm{c}}$, and the amount of decreasing rate increases with $f_{1} / f_{c}$. The value of $f_{c}$ is in general higher for small earthquakes than for large ones. Hence, under-estimates of $\mathrm{E}_{\mathrm{s}}$ are higher for small earthquakes than for large ones.

Figure 3 shows that for fixed $f_{c}, E_{\mathrm{s} 2} / E_{\mathrm{so}}$, and $E_{\mathrm{s} 3} / \mathrm{E}_{\mathrm{so}}$ decrease with increasing $f_{1}$ and increase increases with decreasing $\mathrm{f}_{1}$. When $\mathrm{f}_{1} / \mathrm{f}_{\mathrm{c}}<0.4$ for $\mathrm{E}_{\mathrm{s} 2} / \mathrm{E}_{\mathrm{so}}$ and $\mathrm{f}_{1} / \mathrm{f}_{\mathrm{c}}<0.2$ for $\mathrm{E}_{\mathrm{s} 3} / \mathrm{E}_{\mathrm{so}}$, the curves are almost flat. This indicates that $f_{1}=0.4 f_{c}$ for $E_{\mathrm{s} 2} / E_{\mathrm{so}}$ and $f_{1}=0.2 f_{c}$ for $E_{\mathrm{s} 3} / E_{\mathrm{so}}$ are the respective optimum lower bounds for stable $\mathrm{E}_{\mathrm{s}}$. Figure 4 shows

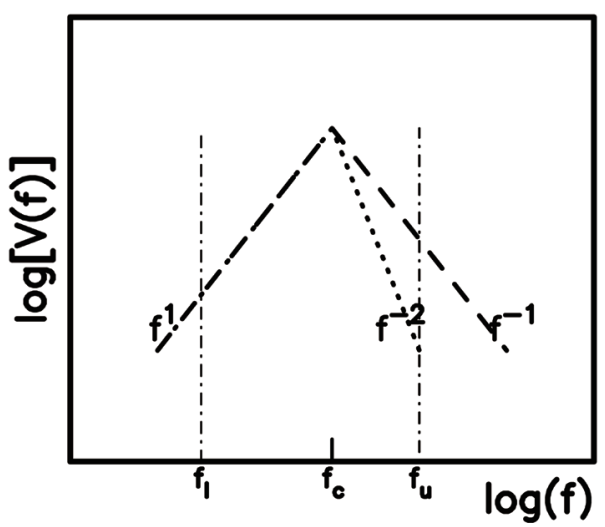

Fig. 2. The log-log plots of the normalized, simplified velocity spectra, $\mathrm{V}(\mathrm{f})$ versus frequency, f: the dashed and dotted lines, respectively, for the $\omega^{-1}$ and $\omega^{-2}$ source velocity models. The two vertical dashed-dotted lines display the frequency band in use (after Wang and Huang 2007). 


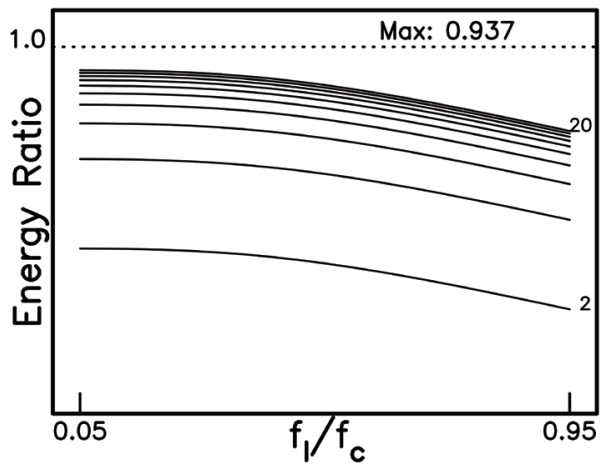

Fig. 3. The variations in $\mathrm{E}_{\mathrm{s} 2}{ }^{\prime} / \mathrm{E}_{\mathrm{s}}$ with $\mathrm{f}_{1} / \mathrm{f}_{\mathrm{c}}$ (from 0.05 - 0.95 ) for ten values for $\mathrm{f}_{\mathrm{u}} / \mathrm{f}_{\mathrm{c}}$ (from $2-20$ ). The dotted line represents $E_{\mathrm{s} 2}{ }^{\prime} / \mathrm{E}_{\mathrm{s}}=1$ (after Wang and Huang 2007).

that $\mathrm{E}_{\mathrm{s} 2} / \mathrm{E}_{\mathrm{so}}$ and $\mathrm{E}_{\mathrm{s} 3} / \mathrm{E}_{\mathrm{so}}$ both increase with $\mathrm{f}_{\mathrm{u}} / \mathrm{f}_{\mathrm{c}}$. The curves are close to one another for $\mathrm{E}_{\mathrm{s} 2} / \mathrm{E}_{\mathrm{so}}$ when $\mathrm{f}_{\mathrm{u}} / \mathrm{f}_{\mathrm{c}} \geq 10$ and for $E_{s} 3 / E_{s o}$ when $f_{u} / f_{c} \geq 4$, thus indicating that $f_{u}=10 f_{c}$ for $E_{\mathrm{s} 2} / E_{\mathrm{so}}$ and $\mathrm{f}_{\mathrm{u}}=4 \mathrm{f}_{\mathrm{c}}$ for $\mathrm{E}_{\mathrm{s} 3} / \mathrm{E}_{\mathrm{so}}$ can lead stable $\mathrm{E}_{\mathrm{s}}$. For fixed $\mathrm{f}_{\mathrm{c}}$, increases in $\mathrm{E}_{\mathrm{s} 2} / \mathrm{E}_{\mathrm{so}}$ and $\mathrm{E}_{\mathrm{s} 3} / \mathrm{E}_{\mathrm{so}}$ with $\mathrm{f}_{\mathrm{u}} / \mathrm{f}_{\mathrm{c}}$ yield increases in the two ratios with $f_{u}$, thus indicating that an increase in $\mathrm{f}_{\mathrm{u}}$ improves estimates of $\mathrm{E}_{\mathrm{s}}$. The results obtained by Wang (2004) and Wang and Huang (2007) are consistent with those made by others (e.g., Boore 1986; Di Bona and Rovelli 1988; Singh and Ordaz 1994; Ide and Beroza 2001).

Figures 3 and 4 show that for fixed $\mathrm{f}_{1}$, the energy ratios decrease with increasing $f_{l} / f_{c}$ and thus they increase with $\mathrm{f}_{\mathrm{c}}$. This implies that the FFBL effect in the low-frequency regime gives a greater underestimate of $\mathrm{E}_{\mathrm{s}}$ for events with lower $f_{c}$ than for those with higher $f_{c}$. This effect is stronger for the $\omega^{-3}$ model than the $\omega^{-2}$ model.

\subsubsection{The Site Effect}

Observations show that seismic waves are amplified at sedimentary sites (Wang et al. 2002; Huang et al. 2005, $2007,2009)$, because the seismic waves are amplified when they propagate through the low-shear-velocity and low-density layers. The amplification of seismic waves is usually a function of frequency and stronger at a soil site than at a rock one. The site classification criteria used in the USA (see Huang et al. 2005, 2007, 2009) are based on $V_{30}$, which is the averaged shear velocity from the ground surface to $30-\mathrm{m}$ depth: the Class-A site with $\mathrm{V}_{30}>1500 \mathrm{~m} \mathrm{sec}^{-1}$, the Class-B one with $\mathrm{V}_{30}=760-1500 \mathrm{~m} \mathrm{~s}^{-1}$, the Class-C one with $\mathrm{V}_{30}=$ $360-760 \mathrm{~m} \mathrm{~s}^{-1}$, the Class-D one with $\mathrm{V}_{30}=180-360 \mathrm{~m} \mathrm{~s}^{-1}$, and the Class-E one with $\mathrm{V}_{30}<180 \mathrm{~m} \mathrm{~s}^{-1}$. Based on the criteria, numerous strong-motion stations are built on the soil sites. The site amplifications could result in over-estimates of $E_{s}$. Hence, it is necessary to correct the site effect. From the quarter-wavelength approximation method proposed by Boore and Joyner (1997) and Huang et al. $(2005,2007)$ evaluated the frequency-dependent site amplifications at 87

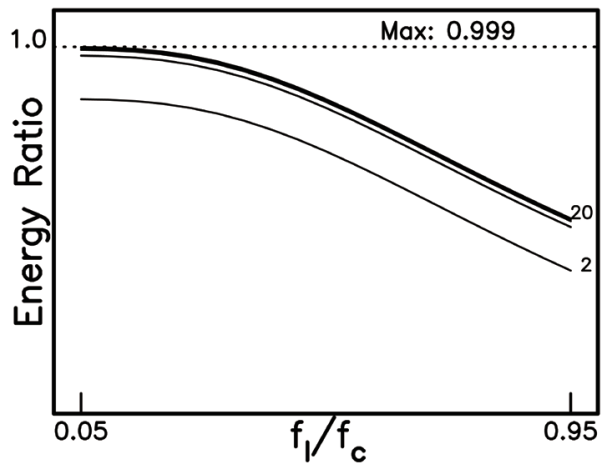

Fig. 4. The variations in $\mathrm{E}_{\mathrm{s} 3}, \mathrm{E}_{\mathrm{s}}$ with $\mathrm{f}_{\mathrm{l}} / \mathrm{f}_{\mathrm{c}}$ (from 0.05 - 0.95 ) for ten values for $\mathrm{f}_{\mathrm{u}} / \mathrm{f}_{\mathrm{c}}$ (from $\left.2-20\right)$. The dotted line represents $\mathrm{E}_{\mathrm{s} 3}{ }^{\prime} / \mathrm{E}_{\mathrm{s}}=1$ (after Wang and Huang 2007).

free-field strong-motion stations in central Taiwan from the velocity and density structures constructed from well-logging data measured in shallow holes near station sites and the average velocity models for the area inferred from earthquake data by Chen et al. (2001) and Satoh et al. (2001). Well-logging velocities measured at shallow and deep holes suggest velocity reliability, at least in the upper $2000 \mathrm{~m}$, inferred by earthquake data. Huang et al. (2009) evaluated the frequency-dependent site amplifications from well-logged data in the Taipei Basin. Their results show three key points: (1) there is no Class-A site and only a few Class-B sites in the study area; (2) the site amplifications are the largest at Class-E sites, intermediate at Class-D, and smallest at Class$\mathrm{C}$; and (3) in spite of wave attenuation, the site amplification increases with frequency for all classes. Point (1) suggests that site amplification removal is strongly necessary for measuring $E_{s}$ especially from strong-motion seismograms. Together with regional geology, point (2) leads to site amplification being larger in the Western Plain with thick Holocene alluvium than in the Western Foothill with Pleistocene and Miocene formations.

\subsection{Fracture Energy}

The fracture energy $E_{g}$ is the energy used to extend the fault plane and can be influenced by numerous factors. Husseini et al. (1975) related $E_{\mathrm{g}}$ to the stress drop and characteristic radius of a fault. From laboratory experiments and numerical simulations, Fialko and Rubin (1997) observed an increase in fracture energy with confining pressure. However, it is difficult to examine this correlation just from seismological observations. Kanamori and Heaton (2000) considered that $\mathrm{E}_{\mathrm{g}}$ can be evaluated using the following equation:

$E_{g}=\left[\left(1-v_{R} / \beta\right) /\left(1+v_{R} / \beta\right)\right]^{1 / 2} \Delta \sigma_{d} \bar{u} S / 2$

where $v_{R}$ and $\beta$ are, respectively, the rupture and $S$-wave 
velocities. This equation is valid only for a crack-like rupture model (Tinti et al. 2005), and $\mathrm{E}_{\mathrm{g}}$ computed from Eq. (8) is an average global value, because $\Delta \sigma_{\mathrm{d}}$ and $\bar{u}$ are both average values over the fault plane. $\mathrm{E}_{\mathrm{g}}$ obviously depends on $\mathrm{v}_{\mathrm{R}} / \beta$, and is much smaller than $\Delta \mathrm{E}$ because of $\mathrm{v}_{\mathrm{R}} / \beta=0.75-0.85$ (Kanamori and Heaton 2000). $\mathrm{G}=\mathrm{E}_{\mathrm{g}} / \mathrm{S}$ is defined as the fracture energy density (per unit area). From the definition, $G$ must be a local parameter. However, in practice only the $G$ value on a certain portion of a fault plane or the whole fault plane can be measured and thus only the global $\mathrm{G}$ average is calculated. In general, $\mathrm{G}$ is $10^{6}-10^{7} \mathrm{~J} \mathrm{~m}^{-2}$ for earthquakes (see Scholz 1990; Ide 2003; Rice et al. 2005; Tinti et al. 2005).

\subsection{Frictional Energy and Heat}

From $E_{f}=\Delta E-\left(E_{s}+E_{g}\right)$, we can obtain the frictional energy. On a fault area of $\mathrm{S}$, heat produced by $\sigma_{\mathrm{d}}$ in an average displacement $\overline{\mathrm{u}}$ during faulting is $E_{\mathrm{f}}=\sigma_{\mathrm{d}} \overline{\mathrm{u}} \mathrm{S}$, and $\mathrm{E}_{\mathrm{f}}$ yields a temperature rise of $\Delta \mathrm{T}$. Assuming that heat is distributed within a layer of thickness $h$ around the ruptured plane, $\Delta \mathrm{T}$ is

$\Delta \mathrm{T}=\mathrm{E}_{\mathrm{f}} / \mathrm{C} \rho \mathrm{Sh}$

where $\mathrm{C}$ and $\rho$ are, respectively, the specific heat and density (Kanamori and Heaton 2000). For crustal rocks, $\mathrm{C}=10^{3} \mathrm{~J} / \mathrm{kg}^{\circ}{ }^{\circ} \mathrm{C}$ and $\rho=2.6 \times 10^{3} \mathrm{~kg} \mathrm{~m}^{-3}$. The heat strength is defined as $\mathrm{Q}=\mathrm{E}_{\mathrm{f}} / \mathrm{C} \rho \mathrm{S}=\Delta \mathrm{T} \cdot \mathrm{h}$.

In order to study the relationship among frictional strength, pore pressure and heat, Wang (2006b) constructed a 2-D (thrust) faulting model with frictional heat. A brief description about his model is given below. The lithostatic pressure $\sigma_{\mathrm{LS}}$ at the average fault depth, $\mathrm{H}$, is $\rho \mathrm{gH}$. The (maximum) horizontal principal stress $\sigma_{1}$ is $\rho \mathrm{gH}$ plus an additional tectonic stress, and the (minimum) vertical principal stress is $\sigma_{3}=\sigma_{\mathrm{LS}}$. The normal and shear stresses, i.e., $\sigma_{\mathrm{n}}$ and $\sigma_{\mathrm{s}}$, on the fault plane with a dip angle of $\theta$ are both a function of $\sigma_{1}$ and $\sigma_{3}$. The relation of $\sigma_{n}$ versus $\sigma_{s}$ is in the form: $\left|\sigma_{\mathrm{s}}\right|=\mu_{\mathrm{f}}\left(\sigma_{\mathrm{n}}-\mathrm{p}_{\mathrm{w}}\right)$, where $\mu_{\mathrm{f}}$ is the frictional coefficient and $\mathrm{p}_{\mathrm{w}}$ is the pore pressure. Let $\mathrm{p}_{\mathrm{w}}=\gamma \rho \mathrm{gH}$, where $\gamma$ is the porefluid factor (cf. Sibson 1992). At shallow depths, where the fluid gradient is hydrostatic and $\gamma$ is the ratio of fluid to rock density, typically $\sim 0.4$. At depths, where the fluid pressure may become suprahydrostatic, $\gamma>0.4$, with an extreme of $\gamma \rightarrow 1$. When a fault zone breaks, $\sigma_{\mathrm{o}}\left(=\left|\sigma_{\mathrm{s}}\right|\right)$ drops to $\sigma_{\mathrm{d}}$. Since $\left|\sigma_{\mathrm{s}}\right|=\mu_{\mathrm{f}}(1-\gamma) \sigma_{\mathrm{n}}, \mu_{\mathrm{fe}}=\mu_{\mathrm{f}}(1-\gamma)$ behaves like the effective frictional coefficient. Based on Anderson theory of faulting (cf. Turcotte and Schubert 1982), Wang (2006b) related $\Delta \mathrm{T}$ to several parameters on the fault in the following form:

$\Delta \mathrm{T}=\mathrm{Q} / \mathrm{h}=\xi \mu_{\mathrm{f}}(1-\gamma) \mathrm{gH} \sin (2 \theta) / \mathrm{hC}\left[\left(1+\mu_{\mathrm{f}}^{2}\right)^{1 / 2}-\mu_{\mathrm{f}}\right]$

from this equation we can evaluate the pore pressure on the fault plane.

\subsection{Seismic Efficiency}

The seismic efficiency, $\eta$, is defined as the ratio of $E_{s}$ to $\Delta \mathrm{E}$, i.e., $\eta=\mathrm{E}_{\mathrm{s}} / \Delta \mathrm{E}$, has been long taken to present the level of seismic-wave radiation generated from an earthquake source. The seismic radiation energy can be approximated by $\eta=\Delta \sigma_{d} d\left(\sigma_{o}+\sigma_{f}\right)(\mathrm{cf}$. Scholz 1990). Although the dynamic stress drop, $\Delta \sigma_{\mathrm{d}}$, can be determined from seismograms, the total stress must be evaluated from non-seismic data. Hence, the seismic radiation energy, which obviously depends upon the total stress, cannot be determined only from seismological observations. When $\Delta \sigma_{\mathrm{d}}$ is constant, $\eta$ decreases with increasing total stress. Hence, the seismic efficiency can reflect the regional tectonics. Savage and Wood (1971) assumed $\eta \leq 0.07$. Spottiswoode and McGarr (1975) reported $\eta \leq 0.01$ for the mine tremors. Boatwright (1978) reported $\eta=0.08$ for an $\mathrm{M}_{\mathrm{L}} 1.5$ event. Kikuchi (1992) reported $\eta=$ $0.012-0.22$ for 27 large earthquakes and stated that deep events have a smaller value than shallow ones. Kanamori et al. (1998) gave $\eta=0.04$ for the 1994 deep Bolivia earthquake. From laboratory experiments and mining-induced events $(M=-1.9$ to 3.3), McGarr $(1994,1999)$ hypothesized $\eta \leq 0.06$ and stated that this hypothesis holds for both small and large events. However, those authors estimated $\eta$ mainly from seismic data under some assumptions. I assume that the slip distribution inferred from seismic data cannot completely reflect the static strain field on the fault plane, which is the basis for measuring $\Delta \mathrm{E}$. The seismograms used for source inversion usually consist only of shorter-period signals. Hence, their previous estimates of $\eta$ are problematic.

\subsection{Radiation Efficiency}

As mentioned above, the uncertainty of evaluating $\eta$ is high due to the difficulty in accurately measuring $\Delta \mathrm{E}$. Hence, Kanamori and Heaton (2000) defined a new parameter, i.e., the radiation efficiency, $\eta_{R}$, which is $\eta_{R}=E_{s} /\left(E_{s}+E_{g}\right)$. This parameter can be evaluated directly from seismograms. Venkataraman and Kanamori (2004) observed $\eta_{R}=0.25-1$ for most of earthquakes.

Kanamori (2004) related the radiation efficiency to the grain size and physical properties of slip zone on a fault using the following approximated formula:

$\eta_{\mathrm{R}}{ }^{\prime}=1 /\left[1+6 \lambda \mathrm{G}_{\mathrm{c}}\left(\mathrm{t}_{\mathrm{s}} / \mathrm{D}_{\max }\right) / \mu \mathrm{e}_{\mathrm{R}} \mathrm{d}\right]$

where $\lambda$ is the correction for grain roughness, $\mathrm{G}_{\mathrm{c}}$ is specific fracture energy, $t_{s} / D_{\max }$ is the ratio of the slip thickness $\left(t_{s}\right)$ to the total displacement $\left(D_{\max }\right), e_{R}$ is the scaled energy which was defined by Kanamori (1977) and will be explained below, and $d$ is the average grain size. Obviously, $\eta_{R}$ ' is 
slightly different from $\eta_{\mathrm{R}}$.

The radiation efficiency is strongly affected by the variation in shear stress with slip (see Fig. 1). Wang (2009) considered thermal pressurization to be a significant mechanism in controlling the variation in shear stress, thus influencing $\eta_{R}$. He derived the formula for $\eta_{R}$ as a function of slip, $\delta$, based on the two end-member models of thermal pressurization, i.e., the adiabatic-undrained-deformation (AUD) and slip-on-a-plane (SOP) models, proposed by Rice (2006). His formula are

$\eta_{\text {RAUD }}=1-\frac{2\left[1-\left(1+\delta / \delta_{c}\right) \exp \left(-\delta / \delta_{c}\right)\right]}{\left[1-\exp \left(-\delta / \delta_{c}\right)\right]\left(\delta / \delta_{c}\right)}$

for the AUD model and

$\eta_{\mathrm{RSOP}}=1-\frac{2\left[\begin{array}{l}\left(1-\delta / \mathrm{L}^{*}\right) \exp \left(\delta / \mathrm{L}^{*}\right) \operatorname{erfc}\left(\delta / \mathrm{L}^{*}\right)^{1 / 2} \\ -1+2\left(\delta / \pi \mathrm{L}^{*}\right)^{1 / 2}\end{array}\right]}{\left[1-\exp \left(\delta / \mathrm{L}^{*}\right) \operatorname{erfc}\left(\delta / \mathrm{L}^{*}\right)^{1 / 2}\right]\left(\delta / \mathrm{L}^{*}\right)}$

for the SOP model. Obviously, the radiation efficiency is mainly controlled by $\delta / \delta_{\mathrm{c}}$ for the AUD model and by $\delta / \mathrm{L}^{*}$ for the SOP model. Equations (12) and (13) show that $\eta_{\text {RAUD }}$ and $\eta_{\mathrm{RSOP}}$ are zero when $\delta=0$ and 1 when $\delta$ approaches infinity.

The controlling parameters of the AUD and SOP models are, respectively, $\delta_{\mathrm{c}}$ and $\mathrm{L}^{*}$ which are individually in terms of thermal, mechanical, and hydraulic parameters of fault rocks. Modeled results suggest that thermal pressurization controls the variation in shear stress with slip and thus influence the radiation efficiency. Results show that $\eta_{\mathrm{R}}$ increases with $\delta$. The increasing rate of $\eta_{R}$ with $\delta$ is high at small $\delta$ and low at large $\delta$. This indicates that $\eta_{\mathrm{R}}$ varies very much with $\delta$ for small earthquakes and only slightly depends on $\delta$ for large events. For the two end-member models, $\eta_{\mathrm{R}}$ increases with decreasing $\delta_{\mathrm{c}}$ (or $\left.\mathrm{L}^{*}\right)$. When $\delta_{\mathrm{c}}=\mathrm{L}^{*}, \eta_{\mathrm{R}}$ is higher for the AUD model than for the SOP model.

\section{MEASURES OF EARTHQUAKE ENERGIES IN TAIWAN}

\subsection{Early Studies}

Based on the GR law, Hsu (1971) first measured the temporal variations in $\mathrm{E}_{\mathrm{s}}$ of $\mathrm{M} \geq 5$ earthquakes in the Taiwan region from 1936 - 1969. The total release of $E_{s}$ during the study period of time for the region was $1.062 \times 10^{24} \mathrm{ergs}$ for $M \geq 5$ earthquakes and $0.956 \times 10^{24}$ ergs for $M \geq 6$ events. The mean annual energy release rate during the study period of time for the region is $3.50 \times 10^{22}$ ergs year $^{-1}$ for $\mathrm{M} \geq 5$ earthquakes and $2.66 \times 10^{22} \mathrm{ergs}$ year $^{-1}$ for $\mathrm{M} \geq 6$ events. The latter is about one hundredth as much as the rate $(=2.85$ $\times 10^{24} \mathrm{ergs}$ year $\left.^{-1}\right)$ for the global earthquakes. Hsu (1973) re-estimated the mean rate of $E_{\mathrm{s}}$ of $\mathrm{M} \geq 6$ earthquakes, and his new value is $4.174 \times 10^{22} \mathrm{ergs}$ year $^{-1}$, which is about 1.6 times of the previous value. However, the earthquake magnitude scale used by Hsu $(1971,1973)$ was Hsu' magnitude, $\mathrm{M}_{\mathrm{H}}$, rather than the surface-wave magnitude, which appears in the GR law. Wang (1992) showed that $M_{H}$ relates to $M_{s}$ in the form of $\mathrm{M}_{\mathrm{s}}=-0.95+1.15 \mathrm{M}_{\mathrm{H}}$, and thus $\mathrm{M}_{\mathrm{H}}>\mathrm{M}_{\mathrm{s}}$ when $M_{H}<6.3$ and $M_{H}<M_{s}$ when $M_{H}>6.3$. This indicates that $E_{s}$ was over-estimated for $\mathrm{M}_{\mathrm{H}}<6.3$ earthquakes and under-estimated for $M_{H}>6.3$ events by Hsu $(1971,1973)$. Chen and Wang (1985) measured the $E_{s}$ of $M \geq 4$ earthquakes occurred during the $1973-1984$ period in the Taiwan region with numerous units of $20^{\prime} \times 20^{\prime}$. Since they used the duration magnitude for the GR law, the calculated value of $E_{\mathrm{s}}$ should be revised. From the strong-motion seismograms recorded by the SMART-1 array generated by 21 near-earthquakes $\left(\mathrm{M}_{\mathrm{s}}\right.$ $=4.1-7.8$ ) with focal depths from $1-98 \mathrm{~km}$, Bolt and Wen (1990) measured the values of $E_{\mathrm{s}}$ of those events using the integral of the square of the ground velocity. The measured

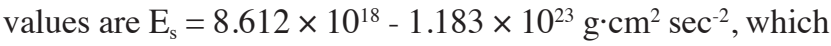
are higher than those calculated from the GR law. Since the FFBL and site effects were not eliminated in their measures, their results are questionable. Chang and Shin (1994) measured the cumulative values of $E_{\mathrm{s}}$ for Taiwan earthquakes occurred in 1993. However, their earthquake magnitude scale was local magnitude, $\mathrm{M}_{\mathrm{L}}$, estimated from the simulated Wood-Anderson seismograms made from short-period seismograms, proposed by Shin (1993). Obviously, $\mathrm{M}_{\mathrm{L}}$ is different from $\mathrm{M}_{\mathrm{s}}$. Hence, it is necessary to correct the cumulative values of $E_{s}$ estimated by Chang and Shin (1994).

\section{2 $1999 \mathrm{M}_{\mathrm{s}}$ 7.6 Chi-Chi Earthquake}

On 20 September 1999, the $\mathrm{M}_{\mathrm{s}}$ 7.6 Chi-Chi earthquake ruptured the Chelungpu fault, which is a $\sim 100-\mathrm{km}$-long and east-dipping thrust fault, with a dip angle of $30^{\circ}$, in central Taiwan (Ma et al. 1999; Shin and Teng 2001). The epicenter, fault trace, and the fault plane are displayed in Fig. 5. In 2000, two shallow boreholes near the Chelungpu fault (see Figs. 5 and 6) were drilled (cf. Tanaka et al. 2002; Hung et al. 2007). The distances from the drilling site to the fault trace are 500 and $250 \mathrm{~m}$, respectively, for the northern and southern boreholes. From core samples, two fractures zones can be recognized. Hung et al. (2007) stated that the two boreholes encountered the fault plane of the event, and assumed that the possible fracture zone of the Chi-Chi earthquake is at $225-330$ and $177-180 \mathrm{~m}$, respectively, in the northern and southern boreholes. The main results were reported by several authors (Otsuki et al. 2001; Tanaka et al. 2002; Hung et al. 2007; Wang 2010).

Kano et al. (2006) measured he temperature rise in the two shallow boreholes (see Fig. 6) about 1.4 years after the earthquake. The peak temperature values on the fault plane are 0.5 and $0.1^{\circ} \mathrm{C}$, respectively, in the southern and northern 
boreholes. The temperature rise decreases with increasing distance from the fault plane as described by a 1-D cooling equation, from which Mori (2004) estimated the frictional coefficients. Results are: (1) $0.7-1.0$, with an average 0.85 , at the $182-\mathrm{m}$ depth in the south and $0.1-0.2$, with an average 0.15 , at the 320 -m depth in the north; and (2) an average 0.45 for the two segments.

In 2005 the Taiwan Chelungpu-fault Drilling Project (TCDP) was launched (Song et al. 2007a), and thus two deep holes, i.e., Hole-A and Hole-B, with depths of $2000 \mathrm{~m}$ were drilled cutting across the fault plane (see Fig. 6). The two holes are located $40 \mathrm{~m}$ apart. Both are located inside the solid circle of Fig. 5. The fault zone, denoted by the FZA1111, is located at the depth of $\sim 1111 \mathrm{~m}$ below the ground surface. Kano et al. (2006) measured temperatures, with a resolution of $0.003^{\circ} \mathrm{C}$, inside Hole-A in September 2005, six years after the earthquake, i.e., $\mathrm{t}=1.9 \times 10^{8} \mathrm{sec}$. They plotted a spatial distribution of temperature rise, $\Delta \mathrm{T}$, between -40 and $+40 \mathrm{~m}$, i.e., the line segment denoted by TT' in Fig. 6, with the center on the fault plane on which the maximum value is $0.06^{\circ} \mathrm{C}$.

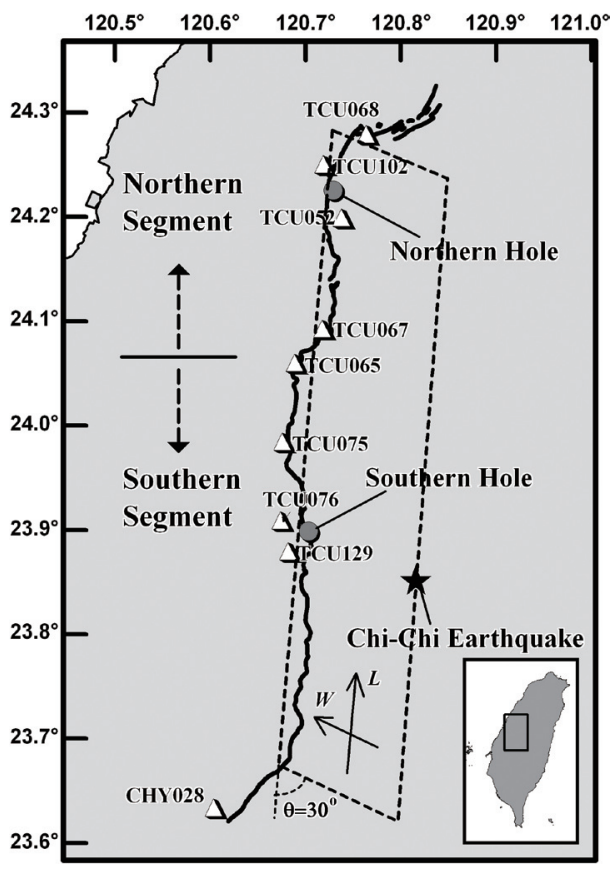

Fig. 5. A figure to show the epicenter (in a solid star), the surface trace of the Chelungpu fault (in a solid line), the fault plane (bounded by four dashed lines), the nine near-fault seismic station sites (in open triangles), and the borehole sites (in solid circles). The northern and southern segments of the fault are separated at a locality near station TCU065 (after Wang 2006b).

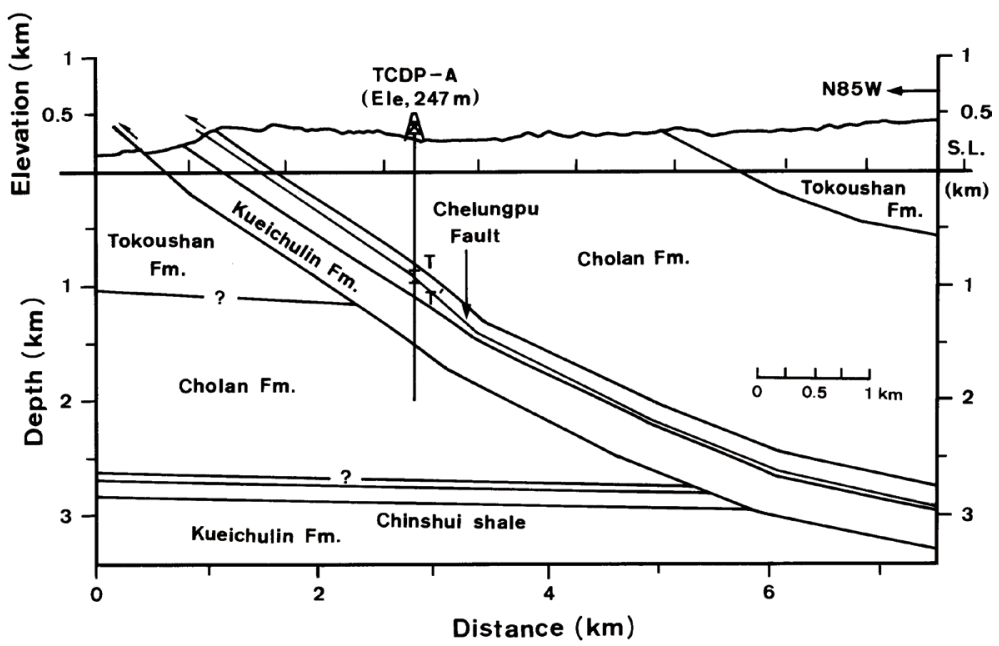

Fig. 6. Structural profile across Hole A [reproduced from Hung et al. (2007)]. Line segment TT' displays the depth range within which temperature was measured by Kano et al. (2006) (after Wang 2006b). 


\subsection{Strain Energy}

As mentioned above, Wang (2004) proposed a method to measure $\Delta \mathrm{E}$ of the earthquake from the slip distribution inferred by Dominguez et al. (2003). For the whole Chelungpu fault, Wang (2004) obtained $\Delta \mathrm{E}=3.206 \times 10^{24} \mathrm{ergs}$, which is equivalent to $M_{s}=8.5$ based on the GR law. On the two segments of the Chelungpu fault, the strain energies are $\Delta \mathrm{E}_{\mathrm{N}}=2.341 \times 10^{24} \mathrm{ergs}$ and $\Delta \mathrm{E}_{\mathrm{S}}=0.865 \times 10^{24} \mathrm{ergs}$ for the northern and southern segments, respectively. The related surface-wave magnitudes are $\mathrm{M}_{\mathrm{s}}=8.4$ and 8.1 for the northern and southern segments, respectively.

\subsection{Seismic Radiation Energy}

Ma et al. $(2000,2001)$ estimated three related source parameters, i.e., $\mathrm{M}_{\mathrm{o}}=2.2 \times 10^{27}$ dyne-cm, $\Delta \sigma_{\mathrm{d}}=2.0 \times 10^{7}$ dyne $\mathrm{cm}^{-2}$, and $\Delta \sigma_{\mathrm{s}}=1.1 \times 10^{7}$ dyne $\mathrm{cm}^{-2}$, from seismic data. This gives $E_{s}=8.39 \times 10^{23} \mathrm{ergs}$ based on Eq. (3). From teleseismic data, Venkataraman and Kanamori (2004) obtained $\mathrm{E}_{\mathrm{s}}=8.8 \times 10^{15} \mathrm{~J}$ and $\eta_{\mathrm{R}}=0.8$ under some assumptions. From the GR law, Wang (2006b) obtained $\mathrm{E}_{\mathrm{s}}=6.31 \times 10^{22} \mathrm{ergs}$ (or $6.31 \times 10^{15} \mathrm{~J}$ ). Obviously, the values of $E_{s}$ evaluated from seismic data are higher than that directly calculated from the GR law. This might be due the reasons that Ma et al. (2000, 2001) and Venkataraman and Kanamori (2004) did not remove the FFBL and site effects from recorded seismograms

Hwang et al. (2001) measured $\mathrm{E}_{\mathrm{s}}$ from the seismograms recorded at nine near-fault seismic stations. Wang (2004) revised their values by eliminating the FFBL effect. For the whole Chelungpu fault, $\mathrm{He}$ obtained $\mathrm{E}_{\mathrm{s}}=4.307 \times 10^{23} \mathrm{ergs}$, which is higher than that calculated from the GR law and equivalent to $\mathrm{M}_{\mathrm{s}}=8.0$ and energy of $\sim 676$ atomic bombs. Obviously, the $\mathrm{M}_{\mathrm{s}}$ value calculated from $\mathrm{E}_{\mathrm{s}}$ is higher than $\mathrm{M}_{\mathrm{s}}$ $=7.6$ that was measured from the maximum ground vertical amplitude by the United States Geological Survey (USGS). For the two segments of the fault, $\mathrm{E}_{\mathrm{sN}}=3.981 \times 10^{23} \mathrm{ergs}$ for the northern segment and $\mathrm{E}_{\mathrm{sS}}=0.326 \times 10^{23} \mathrm{ergs}$ for the southern segments. The related values of $\mathrm{M}_{\mathrm{s}}$ are 7.9 and 7.1, respectively. The $\mathrm{E}_{\mathrm{s}}$ values are equivalent to $\sim 622$ and $\sim 54$ atomic bombs, respectively.

From the values of $\mathrm{E}_{\mathrm{s}}$ and $\Delta \mathrm{E}$ as mentioned above, Wang (2004) obtained the seismic efficiency of the 1999 Chi-Chi earthquake: $\eta=0.137$ (or 13.7\%) for the whole fault, $\eta_{\mathrm{N}}=0.169$ (or 16.9\%) for the northern segment, and $\eta_{\mathrm{S}}=0.038$ (or $3.8 \%$ ) for the southern segment. The $\eta_{\mathrm{N}}$ and $\eta_{\mathrm{S}}$ values lead to about $80 \%$ of $\Delta \mathrm{E}_{\mathrm{N}}$ and $97 \%$ of $\Delta \mathrm{E}_{\mathrm{S}}$ were transferred into the non-seismic radiation energies, mainly including $\mathrm{E}_{\mathrm{g}}$ and $\mathrm{E}_{\mathrm{f}}$. In addition, results cannot completely fit the McGarr's $\eta \leq 0.06$ hypothesis.

Hwang (2012) measured the radiated seismic energy of the $\mathrm{M}_{\mathrm{L}} 6.4$ JiaSian earthquake of 4 March 2010 from teleseismic waves. His measured values are $\mathrm{E}_{\mathrm{s}}=2.91 \times 10^{13} \mathrm{~J}$ and $\mathrm{M}_{\mathrm{o}}=2.17 \times 10^{18} \mathrm{Nm}$, which is associated with $\mathrm{M}_{\mathrm{w}}=$
6.15. Obviously, the estimated seismic-moment magnitude is lower than the local magnitude.

\subsection{Fracture Energy}

From teleseismic data, Venkataraman and Kanamori (2004) obtained $\mathrm{E}_{\mathrm{s}}=0.88 \times 10^{16} \mathrm{~J}$ and $\eta_{\mathrm{R}}=0.8$, thus leading to $E_{g}=0.22 \times 10^{16} \mathrm{~J}$, for the overall fault plane. To calculate $\mathrm{E}_{\mathrm{g}}$ and $\mathrm{G}$ of the Chi-Chi earthquake, Wang (2006b) took the $\mathrm{V}_{\mathrm{R}} / \beta, \Delta \sigma_{\mathrm{d}}$ values and $\mathrm{S}$ from Huang et al. (2001), Ma et al. (2001), and Wang (2004). The related parameter values are: $\left(\mathrm{v}_{\mathrm{R}} / \beta\right)_{\mathrm{S}}=0.75, \Delta \sigma_{\mathrm{dS}}=6.52 \mathrm{MPa}, \mathrm{D}_{\mathrm{S}}=4.88 \mathrm{~m}$, and $\mathrm{S}_{\mathrm{S}}=4.551$ $\times 10^{8} \mathrm{~m}^{2}$ for the northern segment; and $\left(\mathrm{v}_{\mathrm{R}} / \beta\right)_{\mathrm{N}}=0.80, \Delta \sigma_{\mathrm{dN}}$ $=29.7 \mathrm{MPa}, \mathrm{D}_{\mathrm{N}}=7.15 \mathrm{~m}$, and $\mathrm{S}_{\mathrm{N}}=3.615 \times 10^{8} \mathrm{~m}^{2}$ for the northern segment. The $\mathrm{E}_{\mathrm{g}}$ estimate depends on the $\mathrm{D}_{\mathrm{c}}$ value. Wang (2006b) assumed that $D_{c S}=1 \mathrm{~m}$ is acceptable for the southern segment and $\mathrm{D}_{\mathrm{cN}}$ should be in between $1.8-3.7 \mathrm{~m}$ for the northern segment. Hence, the $\mathrm{E}_{\mathrm{g}}, \mathrm{G}$, and $\eta_{\mathrm{R}}$ values are: $E_{\mathrm{gS}}=0.15 \times 10^{16} \mathrm{~J}, \mathrm{G}_{\mathrm{S}}=0.33 \times 10^{7} \mathrm{~J} \mathrm{~m}^{-2}$, and $\eta_{\mathrm{RS}}=0.69$ for the southern segment and $0.95 \times 10^{16} \mathrm{~J}<\mathrm{E}_{\mathrm{gN}}<1.99 \times 10^{16} \mathrm{~J}$, $2.59 \times 10^{7} \mathrm{~J} \mathrm{~m}^{-2}<\mathrm{G}_{\mathrm{N}}<5.34 \times 10^{7} \mathrm{~J} \mathrm{~m}^{-2}$, and $0.67<\eta_{\mathrm{RN}}<$ 0.81 . The related parameter values are higher on the northern segment than on the southern segment.

From local seismograms, Zhang et al. (2003) evaluated the $G$ values. Their results show that $G$ increases from south to north, and $\mathrm{G}_{\mathrm{S}}=10^{5}-10^{8} \mathrm{~J} \mathrm{~m}^{-2}$ in the south and $\mathrm{G}_{\mathrm{N}}$ up to $3 \times 10^{8} \mathrm{~J} \mathrm{~m}^{-2}$ in the north. Their values are about one-order-of-magnitude larger than those of Wang (2006b). From the core sample on the 1111-m slip zone of a 2000-m deep hole, Ma et al. (2006) observed that the thickness of the slip zone is about $0.02 \mathrm{~m}$ and the grain size is in the range $(50-1000) \times 10^{-9} \mathrm{~m}$. From the grain size, they obtained average $\mathrm{G}=4.8 \times 10^{6} \mathrm{~J} \mathrm{~m}^{-2}$, which is about one fifth of that from Wang (2006b) and one-order-of-magnitude smaller than those estimated by Zhang et al. (2003). Obviously, the $\mathrm{G}_{\mathrm{N}}$ values from Wang (2006b) seem better than those from the other two groups.

\subsection{Frictional Energy and Heat}

Mori (2004) inferred frictional energy for the whole fault from model computations. His value is $E_{\mathrm{f}}=3.6 \times 10^{16} \mathrm{~J}$. The values of $\mathrm{Q}_{\mathrm{S}}$ and $\mathrm{Q}_{\mathrm{N}}$, which are, respectively, the heat strength at the southern and northern shallow boreholes, and $(\Delta \mathrm{T})_{\mathrm{S}}=(102 / \mathrm{h})^{\circ} \mathrm{C}$ and $(\Delta \mathrm{T})_{\mathrm{N}}=(154 / \mathrm{h})^{\circ} \mathrm{C}$. As mentioned above, Venkataraman and Kanamori (2004) obtained $\mathrm{E}_{\mathrm{s}}=$ $0.88 \times 10^{16} \mathrm{~J}$ and $\mathrm{E}_{\mathrm{g}}=0.22 \times 10^{16} \mathrm{~J}$ for the overall fault plane, thus leading to $E_{s}+E_{g}=1.10 \times 10^{16} \mathrm{~J}$, which is one fifth of $\mathrm{E}_{\mathrm{s}}+\mathrm{E}_{\mathrm{g}}=5.47 \times 10^{16} \mathrm{~J}$ from Wang (2006b). Using the $\Delta \mathrm{E}$ value from Wang (2006b) and the $\mathrm{E}_{\mathrm{s}}+\mathrm{E}_{\mathrm{g}}=5.47$ $\times 10^{16} \mathrm{~J}$ value from Venkataraman and Kanamori (2004), Wang (2006b) obtained $\mathrm{E}_{\mathrm{f}}=3.09 \times 10^{17} \mathrm{~J}$, which is 8.57 times higher than $0.36 \times 10^{17} \mathrm{~J}$ from Mori (2004), and 1.17 times higher than $2.65 \times 10^{17} \mathrm{~J}$ from Wang (2006b). The 
related Q values are $144.3^{\circ} \mathrm{C}-\mathrm{m}$ from Venkataraman and Kanamori (2004) and $123.9^{\circ} \mathrm{C}-\mathrm{m}$ from Wang (2006b), with a difference of $20.4^{\circ} \mathrm{C}-\mathrm{m}$. The difference is clearly small.

Based on the 1-D heat conduction equation described below, they used several modeled spatial distributions of $\Delta \mathrm{T}$ to fit observed data and then evaluated the optimum values of heat strength $\mathrm{Q}\left(=1.5^{\circ} \mathrm{C}-\mathrm{m}\right)$ and thermal diffusivity $\alpha\left(=3.4 \times 10^{-7} \mathrm{~m}^{2} \mathrm{~s}^{-1}\right)$. Since their optimum model of $\Delta \mathrm{T}$ fits the observations in a large spatial range -40 to $40 \mathrm{~m}$, the inferred value of $\alpha$ must be the average of wall rocks, because the thickness of primary slip zone (PSZ) identified by Ma et al. (2006) is only $0.12 \mathrm{~m}$. Tanaka et al. (2007) measured $\alpha$ directly from the core samples of PSZ. Their results are $(0.8-2.0) \times 10^{-6} \mathrm{~m}^{2} \mathrm{~s}^{-1}$, with $1.0 \times 10^{-6} \mathrm{~m}^{2} \mathrm{~s}^{-1}$ in the major slip zone (MSZ) identified by Ma et al. (2006). Obviously, their values are about 3 times larger than that inferred by Kano et al. (2006). This made heat diffusion faster in the fault zone than in wall rocks.

Kano et al. (2006) measured the temperatures in the depth range -40 to $40 \mathrm{~m}$ with respect to the fault zone at the FZA1111 six years after the earthquake. With $\Delta \mathrm{T}=0.06^{\circ} \mathrm{C}$ at $\mathrm{x}=0$, they inferred $\mathrm{Q}=1.5^{\circ} \mathrm{C}-\mathrm{m}$ and $\alpha=3.4 \times 10^{-7} \mathrm{~m}^{2} \mathrm{~s}^{-1}$. On the other hand Tanaka et al. (2007) assumed that the variation in thermal conductivity between the fault-zone materials and wall rocks caused the spatial variations in temperature measured by Kano et al. (2006). Hence, the Q value inferred by Kano et al. (2006) is questionable.

Tanaka et al. $(2006,2007)$ measured the thermal properties of the fault zone materials across the Chelungpu fault zone activated by the 1999 Chi-Chi earthquake using the drilled core penetrating the fault zone at around $1100 \mathrm{~m}$ depth. The fault zone contains four distinct fracture zones, each of which includes thin slip zones. Thermal conductivity lies between $1.0-3.0 \mathrm{~W} \mathrm{~m}-\mathrm{K}^{-1}$ and shows the lowest value at the slip zones. Thermal diffusivity $(\alpha)$ varies between 0.8 $\times 10^{-6}$ and $2.0 \times 10^{-6} \mathrm{~m}^{2} \mathrm{~s}^{-1}$, and is relatively low at the slip zones. Density $(\rho)$ varies between $2200-2800 \mathrm{~kg} \mathrm{~m}^{-3}$ and shows the lowest values at a particular slip zone $(1110 \mathrm{~m}$ depth). Specific heat (c) is calculated using the above data

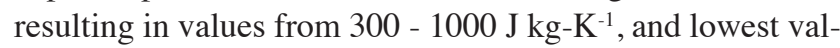
ues for slip zones. Using these data and spectral gamma ray logs, reported positive thermal anomalies at the slip zones are re-examined whether they are regarded as residual heat from friction by faulting.

From laboratory experiments Hirono et al. $(2007,2008)$ interpreted $\sigma_{\mathrm{s}}=1.37 \mathrm{MPa}$ for the black gouge at the FZB1136 of Hole-B. Since the FZB1136 is equivalent to the FZA1111 of Hole-A and almost the same black gouges exist in the fault zones of the two holes, their value is used here. From $\sigma_{\mathrm{d}}=$ $0.8 \sigma_{\mathrm{s}}$, we have $\sigma_{\mathrm{d}}=1.10 \mathrm{MPa}$. Since the study site is close to the ground surface, $\mathrm{D}$ almost equals $\mathrm{D}_{\mathrm{gs}}=4.24 \mathrm{~m}$. Tanaka et al. (2007) obtained $\mathrm{C}_{\mathrm{v}}=300 \mathrm{~J} \mathrm{~kg}^{-1}{ }^{\circ} \mathrm{C}^{-1}$ and $\rho=2200 \mathrm{~kg} \mathrm{~m}^{-3}$ for the MSZ. Inserting into Eq. (3) these values leads to $\mathrm{Q}=$ $7.0^{\circ} \mathrm{C}-\mathrm{m}$, which is about 4.7 times higher than that inferred by Kano et al. (2006). Using the previous data, Wang (2011) calculated the heat strength on the Chelungpu fault plane at a depth of $1111 \mathrm{~m}$ from relevant data obtained from HoleA. The calculated value is $7.0^{\circ} \mathrm{C}-\mathrm{m}$, and is larger than that inferred by Kano et al. (2006), whose evaluation was based on a smaller value of thermal diffusivity of the wall rocks. The thermal history modeled from the 1-D heat conduction model, with the values of thermal diffusivity evaluated in a temperature range based on the Debye law, assumes that frictional heating occurred mainly in a very thin layer, $<5 \mathrm{~mm}$, which is inside the black materials found around the fault plane. This heated layer had a larger thermal diffusivity than wall rocks and was the least deformed part of the fault zone. Calculated results exhibit that the temperature $\mathrm{T}$ increases from the ambient value of $\mathrm{T}_{\mathrm{a}}=46.5^{\circ} \mathrm{C}$ at $\mathrm{t}=0$ to a peak value $\mathrm{T}_{\text {peak }}$ of $\sim 1100^{\circ} \mathrm{C}$ at the rise time $\mathrm{t}_{\mathrm{r}}$ of $\sim 2.5 \mathrm{sec}$ and then decreases with increasing t. Obviously, the frictional heat dissipated rapidly during the earthquake. This provides an answer to the so-called heat flux paradox (Lachenbruch and Sass 1980). There is no high thermal anomaly during faulting due to a remarkable decrease in the effective frictional stress.

Chemical analyses of pseudotachylites and clay minerals (including smectite, illite, kaolinite, and chlorite) of core samples and temperatures measured about six years after the earthquake in a 2000-m hole, which crosses the fault plane, Wang (2011) proposed a positive correlation between the spatial distribution of clay minerals and temperature rise caused by frictional heating during the earthquake. Pseudotachylites could be formed in the heated layer in a very short time interval, $<0.3 \mathrm{sec}$, immediately after faulting. Hence, the amount of pseudotachylite is tiny as observed by Song et al. (2007b). The amount of pseudotachylite and smectite, which was devitrified from black material glasses, is $~ 85 \%$ of the clay minerals inside and low outside the MSZ proposed by Ma et al. (2006). The clay minerals outside the MSZ, $<0.02 \mathrm{~m}$, were very stable during faulting, because of $\mathrm{T}<150^{\circ} \mathrm{C}$.

Based on the 2-D faulting model proposed by Wang (2006b), Wang (2011) evaluated the pore fluid pressure on the depth of $1111 \mathrm{~m}$ at Hole-A during faulting from the values of temperature rise and thermal and mechanical parameters at the hole. A difference of $10^{\circ}$ in the dip angle only yields a small difference in the interpreted pore fluid pressure. The estimated value of the pore-fluid factor is 0.94 , thus leading to a pore fluid pressure of $22.5 \mathrm{MPa}$. Results suggest that the fault zone could have been suprahydrostatic during faulting. The suprahydrostatic pressure reduced the effective friction coefficient and thus decreased frictional heating on the fault plane. This study provides possible causes of a low heat flow on a fault plane.

Wang (2011) assumed that quartz plasticity could be formed in the MSZ when $\mathrm{T}>300^{\circ} \mathrm{C}$ after the study site ruptured. Quartz plasticity could lubricate the fault plane at higher $\mathrm{T}$ and yield viscous stresses to resist slip at lower $\mathrm{T}$. 
The shear zone with quartz plasticity would be localized in a 5-mm thick heated layer.

\subsection{Radiation Efficiency}

From local seismograms Wang (2006b) obtained the optimum values: $(1) \mathrm{E}_{\mathrm{g}}=0.15 \times 10^{16} \mathrm{~J}, \eta_{\mathrm{R}}=0.69$, and $\mathrm{G}=0.33 \times$ $10^{7} \mathrm{~J} \mathrm{~m}^{-2}$ for the southern segment; and (2) $\mathrm{E}_{\mathrm{g}}=1.99 \times 10^{16} \mathrm{~J}$, $\eta_{\mathrm{R}}=0.67$, and $\mathrm{G}=5.34 \times 10^{7} \mathrm{~J} \mathrm{~m}^{-2}$ for the northern segment. From teleseismic data, Venkataraman and Kanamori (2004) obtained $\mathrm{E}_{\mathrm{s}}=0.88 \times 10^{16} \mathrm{~J}$ and $\eta_{\mathrm{R}}=0.8$. Ma et al. (2006) applied Eq. (11) to estimate the radiation efficiency at the drilled site. The values of $G_{c}, T / D$, and $d$ measured from the TCDP by Ma et al. (2006) are: $\mathrm{G}_{\mathrm{c}}=1 \mathrm{~J} \mathrm{~m}^{-2},(\mathrm{~T} / \mathrm{D})=4 \times 10^{-4}$ (due to $\mathrm{T}=12 \mathrm{~cm}$ and $\mathrm{D}=300 \mathrm{~m}$ ), and $\mathrm{d}=1.86 \times 10^{-7} \mathrm{~m}$. The common value of $\mu$ for crustal rocks is $3 \times 10^{30} \mathrm{~Pa}$. The value of $\lambda$ ranges in general from $5-22$ (cf. Wilson et al. 2005). Ma et al. (2006) selected $\lambda=6.6$ for calculations. Consequently, the value of $\eta_{\mathrm{R}}$ ' estimated by them is 0.88 , which is close to $\eta_{R}=0.8$ for the whole fault plane of the Chi-Chi earthquake estimated by Venkataraman and Kanamori (2004) from teleseismic data and larger than $\eta_{R}=$ 0.67 for the northern fault plane evaluated by Wang (2006b) from local seismograms. For comparison Wang (2006b) also used Eq. (11) with the upper bound of $\lambda$, i.e., 22 , to calculate $\eta_{R}$ '. He obtained $\eta_{R}{ }^{\prime}=0.68$ which is close to Wang's $\eta_{\mathrm{R}}=0.67$. Ma et al. (2006) inferred the maximum displacement, $\Delta_{\max }$, at the study to be $8.3 \mathrm{~m}$, Wang (2006b) pointed out that when $\Delta_{\max }<10.7 \mathrm{~m}$, thermal pressurization plays a significant role on controlling rupture.

Wang (2006b) also applied Eqs. (12) and (13) to investigate the shear stress-slip function in a $5 \times 5 \mathrm{~km}$ square covering a drilled site on the fault plane of the 1999 Chi-Chi, Taiwan, earthquake inferred from seismograms. Results show that the AUD model is more appropriate to describe the inferred shear stress-slip function than the SOP model. He stressed that a more acceptable model is a modified one from the AUD model by including a small amount loss of frictional heat from the slip zone during faulting.

\section{SCALED ENERGY}

Kanamori (1977) defined the scaled energy as the ratio of seismic radiation energy to seismic moment, i.e., $\mathrm{e}_{\mathrm{R}}$ $=\mathrm{E}_{\mathrm{s}} / \mathbf{M}_{\mathrm{o}}$. It can be written as $\left(2 \Delta \sigma_{\mathrm{d}}-\Delta \sigma_{\mathrm{s}}\right) / 2 \mu$ (Kanamori and Heaton 2000). When the stresses fully drop, with $\Delta \sigma_{\mathrm{d}}=\Delta \sigma_{\mathrm{s}}$ $=\Delta \sigma$, we have $\mathrm{E}_{\mathrm{s}} / \mathrm{M}_{\mathrm{o}}=\Delta \sigma / 2 \mu$. The ratio $\mathrm{E}_{\mathrm{s}} / \mathrm{M}_{\mathrm{o}}$ multiplied by $\mu$ was introduced as the "apparent stress" in seismology (Aki 1966; Wyss and Brune 1968). It can also be written as a product of $\eta$ and the average stress $\sigma_{\mathrm{a}}=\left(\sigma_{\mathrm{o}}+\sigma_{\mathrm{f}}\right) / 2$, neither of which can be directly determined seismologically. Either $\sigma_{\mathrm{a}}$ or $\mathrm{e}_{\mathrm{R}}$, combined with static stress drop, provides useful information for the state of stress in different tectonic provinces. Vassiliou and Kanamori (1982) observed $\mathrm{E}_{\mathrm{s}} / \mathrm{M}_{\mathrm{o}}=2$ $\times 10^{-4}$ for shallow earthquake and $4.6 \times 10^{-5}$ for deep and intermediate events. For the earthquakes $\left(M_{L}=-1-5\right)$ located near the Cajon Pass scientific drill hole, southern California, Abercrombie (1995) observed that $\mathrm{E}_{\mathrm{s}} / \mathrm{M}_{\mathrm{o}}$ increases with magnitude, and $e_{R}=2 \times 10^{-4}$ when $\mathrm{M}_{\mathrm{o}}>10^{14} \mathrm{Nm}$ and $\mathrm{e}_{\mathrm{R}}$ $>2 \times 10^{-4}$ when $\mathrm{M}_{\mathrm{o}}<10^{14} \mathrm{Nm}$. Kikuchi and Fukao (1988) observed $\mathrm{E}_{\mathrm{s}} / \mathrm{M}_{\mathrm{o}}=10^{-6}-10^{-5}$, with an average of $\sim 5.0 \times 10^{-6}$. Izutani and Kanamori (2001) observed an increase in $\mathrm{E}_{\mathrm{s}} / \mathrm{M}_{\mathrm{o}}$ with the earthquake size for 8 earthquakes $\left(3.6 \leq \mathrm{M}_{\mathrm{w}} \leq 6.6\right)$ in Japan. Kanamori and Heaton (2000) and Prejean and Ellsworth (2001) found an increase in $E_{s} / M_{o}$ is a function of earthquake magnitude. Large earthquakes $\left(\mathrm{M}_{\mathrm{w}}>6\right)$ have values of $\sim 10^{-4}$ while the small ones $\left(\mathrm{M}_{\mathrm{w}}<4\right)$ have values of $\sim 10^{-6}$. The transition of $\mathrm{E}_{\mathrm{s}} / \mathrm{M}_{\mathrm{o}}$ occurs almost at $\mathrm{M}_{\mathrm{w}}=5$. Brodsky and Kanamori (2001) used an elastohydrodynamic lubrication model to elucidate such a change. Based on the spontaneous rupture model, Ma and Archuleta (2006) theoretically computed the values of $E_{s}$ and $M_{0}$. For some values of specified model parameters, they obtained $\mathrm{E}_{\mathrm{s}}=6.0 \times 10^{14} \mathrm{~J}$, and $\mathrm{M}_{\mathrm{o}}=1.47 \times 10^{19} \mathrm{Nm}$, thus giving $\mathrm{e}_{\mathrm{R}}=4.08 \times 10^{-5}$.

Theoretically, Kanamori and Rivera (2004) considered that the $\mathrm{M}_{\mathrm{o}} \sim \mathrm{f}_{\mathrm{c}}^{-3}$ scaling relation leads to independence of $\mathrm{E}_{s} / \mathrm{M}_{\mathrm{o}}$ on earthquake magnitude. They proposed that when the $M_{o}$ versus $f_{c}$ scaling is modified from $M_{o} \sim f_{c}^{-3}$ to $M_{o}$ $\sim \mathrm{f}_{\mathrm{c}}{ }^{-(3+\varepsilon)}(0<\varepsilon \leq 1)$, the scaled energy can be a function of earthquake magnitude. They also obtained that the optimum value of $\varepsilon$ is 0.5 . Previous observations show that $\Delta \sigma / 2 \mu$ is not constant and varies from small events to large ones, thus suggesting that small earthquakes are not similar to large ones. Hence, the GR law which was inferred from large earthquakes cannot be extended to small events.

Wang (2013) studied the correlation of $e_{R}$ versus $M_{s}$ using two models proposed by Beresnev and Atkinson (1997): (1) the first one is the time function of the average displacements, with an $\omega^{-2}$ spectrum, across a fault plane; and (2) the second one is the time function of the average displacements, with an $\omega^{-3}$ spectrum, across a fault plane. Model 1 gives independence of $e_{R}$ on $M_{s}$, and thus the scaled energy is size-independent. This means that in the extreme state of $\mathrm{E}_{\mathrm{s}} / \mathrm{M}_{\mathrm{o}}$ the two different initial conditions, which associated with different source models, lead to a same conclusion that the scaled energy is of size-independence. For Model 2, there are two cases: (1) As $\tau \fallingdotseq \mathrm{T}$ from a conventional viewpoint, $\log \left(\mathrm{e}_{\mathrm{R}}\right) \sim-\mathrm{M}_{\mathrm{s}}$; and (2) As $\tau<<\mathrm{T}$ from the slippulse concept by Heaton (1990), $\log \left(\mathrm{e}_{\mathrm{R}}\right) \sim-\mathrm{M}_{\mathrm{s}} / 2$. Unlike Kanamori and Rivera (2004) and Model 1, Model 2 leads to a negative correlation of scaled energy versus earthquake magnitude. The results obtained from the three different models suggest that the source model, including the scaling law and the relation between $\tau$ and $\mathrm{T}$, is a factor, yet not a unique one, in controlling the correlation of $e_{R}$ versus $M_{s}$. This correlation will depend upon whether the extreme state of $E_{s} / M_{0}$ is taken into account or not. At present it is not yet known which model is the most appropriate one to explain 
the correlation of $e_{R}$ versus $M_{s}$, because the observed correlation is still questionable due to high uncertainties in the estimates of $E_{s}$, especially for large earthquakes.

On the contrary, Ide and Beroza (2001) used an adjustment factor to account for the probable missing energy, and then observed that $E_{\mathrm{s}} / \mathrm{M}_{\mathrm{o}}$ is almost a constant of $\sim 3 \times 10^{-5}$ in a large range of $M_{w}$ from -4 to 9 or over 17 orders of $M_{0}$. This value of $E_{s} / M_{o}$ is slightly smaller than $5.0 \times 10^{-5}$. For 94 interplate and 74 intraplate earthquakes with $\mathrm{M}_{\mathrm{o}}=10^{13}$ - $10^{18} \mathrm{Nm}$ in the Kanto area, Japan recorded by 27 borehole and 7 surface hard-rock stations, Kinoshita and Ohike (2002) observed $E_{s} / M_{o}=(1.15-12.9) \times 10^{-5}$ which is weakly dependent on $\mathrm{M}_{\mathrm{o}}$. Their average for $\mathrm{E}_{\mathrm{s}} / \mathrm{M}_{\mathrm{o}}$ is slightly larger than $5.0 \times 10^{-5}$. Yamada et al. (2007) found that the values of $\mathrm{E}_{\mathrm{s}} / \mathrm{M}_{\mathrm{o}}$ of micro-earthquakes in a gold mine are comparable to those of large earthquakes.

Figure 7 demonstrates the plot of $E_{s} / M_{o}$ versus $M_{s}$ from the data in use (Wang 2015). The horizontal dashed line represents $\mathrm{E}_{\mathrm{s}} / \mathrm{M}_{\mathrm{o}}=5.0 \times 10^{-5}$. The data points from Iio (1986) shows a change of $E_{s} / M_{o}$ from small events to large ones at $\mathrm{M}_{\mathrm{s}}=2.5$, which is smaller than the transition magnitude $\left(M_{s}=5\right)$ proposed by Brodsky and Kanamori (2001). This might be due to under-estimates of $\mathrm{E}_{\mathrm{s}}$ for micro-events by Iio (1986). The overall distribution of $E_{s} / M_{o}$ versus $M_{s}$ is quite uniform and around the horizontal dashed line with $\mathrm{E}_{\mathrm{s}} / \mathrm{M}_{\mathrm{o}}=$ $5.0 \times 10^{-5}$ and there is not a transition at $\mathrm{M}_{\mathrm{s}}=5$. Obviously, $\mathrm{E}_{\mathrm{s}} / \mathrm{M}_{\mathrm{o}}$ is approximately a constant for the present data.

From the strong-motion seismograms recorded by the SMART-1 array generated by 21 near-earthquakes $\left(\mathrm{M}_{\mathrm{s}}=\right.$ 4.1 - 7.8) with focal depths from $1-98 \mathrm{~km}$, Bolt and Wen (1990) measured the values of $M_{0}$. The measured values are $\mathrm{M}_{\mathrm{o}}=6.0 \times 10^{23}-1.3 \times 10^{27}$ dyne $\cdot \mathrm{cm}$. From their measured values of $E_{\mathrm{s}}$ as mentioned above, they obtained $\mathrm{E}_{\mathrm{s}} / \mathrm{M}_{\mathrm{o}}=$ $(4.25 \pm 0.12) \times 10^{-4}$., which is about one-order magnitude larger than the common value of $5.0 \times 10^{-5}$. This might be due to over-estimates of $E_{s}$, because they did not eliminate the FFBL and site effects.

From teleseismic data the $\mathrm{e}_{\mathrm{R}}$ value for the Chi-Chi earthquake evaluated by Venkataraman and Kanamori (2004) is $2 \times 10^{-5}$. Huang et al. (2002) and Huang and Wang (2009) measured the $E_{s}$ and $M_{o}$ values of twenty-two largersized aftershocks with $\left(4.4 \leq \mathrm{M}_{\mathrm{s}} \leq 6.5\right)$ from the 1999 ChiChi, Taiwan, earthquake from local seismograms. Results are: $\mathrm{E}_{\mathrm{s}}=2.0 \times 10^{18}-8.9 \times 10^{21}$ dyne $\cdot \mathrm{cm}$ and $\mathrm{M}_{\mathrm{o}}=1.3 \times$ $10^{23}-1.4 \times 10^{26} \mathrm{~cm} \cdot$ dyne, thus leading to $\mathrm{E}_{\mathrm{s}} / \mathrm{M}_{\mathrm{o}}=7.4 \times 10^{-6}$ - $2.6 \times 10^{-4}$. The $\mathrm{E}_{\mathrm{s}} / \mathrm{M}_{\mathrm{o}}$ values of the 22 events are dependent upon $\mathrm{M}_{\mathrm{s}}$. They also used the $\mathrm{M}_{\mathrm{o}}$ values measured from teleseismic data to calculate $\mathrm{E}_{\mathrm{s}} / \mathrm{M}_{\mathrm{o}}$. The results show $\mathrm{E}_{\mathrm{s}} / \mathrm{M}_{\mathrm{o}}$ independence from $\mathrm{M}_{\mathrm{s}}$ when teleseismic $\mathrm{M}_{\mathrm{o}}$ values are used. They also measured the corner frequency, $\mathrm{f}_{\mathrm{c}}$. Their results ranged from $0.15-1.34$. The scaling law between $\mathrm{M}_{\mathrm{o}}$ and $\mathrm{f}_{\mathrm{c}}$ is $\mathrm{M}_{\mathrm{o}} \sim \mathrm{f}_{\mathrm{c}}^{-3.65}$.

From the measured values of $\mathrm{E}_{\mathrm{s}}$ and $\mathrm{M}_{\mathrm{o}}$ by Hwang (2012) for the M 6.4 JiaSian earthquake of 10 March 2010 as mentioned above, the scaled energy of the event is $E_{s} / M_{0}$ $=1.3 \times 10^{-5}$, which is lower than ordinary earthquakes.

\section{ENERGY-MAGNITUDE LAW}

Richter (1935) defined the local magnitude, $\mathrm{M}_{\mathrm{L}}$. from seismograms recorded on the standard Wood-Anderson seismography. Gutenberg (1945) defined the longer-period body-wave magnitude, $\mathrm{m}_{\mathrm{B}}$, and surface-wave magnitude, $\mathrm{M}_{\mathrm{GR}} \cdot \mathrm{M}_{\mathrm{GR}}$ is measured from the maximum ground horizontal surface-wave amplitude, i.e., $A=\left(A_{N}^{2}+A_{E}^{2}\right)^{1 / 2}=\sqrt{ } 2 A_{N}$ or $\sqrt{2} A_{E}$, where $A_{N}$ and $A_{E}$ are the maximum ground horizontal surface-wave amplitudes along the $\mathrm{E}-\mathrm{W}$ and $\mathrm{N}-\mathrm{S}$ directions, respectively, recorded at an epicentral distance of $\Delta=15$ $130^{\circ}$. The wave period in use is $\mathrm{T}=17-23 \mathrm{sec}$.

The relationship between the seismic radiation energy and earthquake magnitude is important in quantifying earthquakes. Using strong-motion data from 18 California earthquakes with $3.9 \leq \mathrm{M}_{\mathrm{L}} \leq 7.3$, Gutenberg and Richter (1956) inferred a relationship between $E_{s}$ and $M_{L}$ in the following form: $\log \left(\mathrm{E}_{\mathrm{s}}\right)=12+1.8 \mathrm{M}_{\mathrm{L}}\left(\mathrm{E}_{\mathrm{s}}\right.$ in erg). Bullen (1955) expressed that Gutenberg and Richter determined a new relationship: $\log \left(\mathrm{E}_{\mathrm{s}}\right)=11+1.6 \mathrm{M}_{\mathrm{GR}}\left(\mathrm{E}_{\mathrm{s}}\right.$ in erg $)$. Gutenberg and Richter (1956) reported that the previous $E_{s}-M_{L}$ relationship is wrong due to over-estimates of $\mathrm{E}_{\mathrm{s}}$. They found a new law: $\log \left(\mathrm{E}_{\mathrm{s}}\right)=5.8+2.4 \mathrm{~m}_{\mathrm{B}}\left(\mathrm{E}_{\mathrm{s}}\right.$ in erg $)$. Based on this relationship: $\mathrm{m}_{\mathrm{B}}=2.50+0.63 \mathrm{M}_{\mathrm{GR}}$, they obtained $\log \left(\mathrm{E}_{\mathrm{s}}\right)=11.8$ $+1.5 \mathrm{M}_{\mathrm{GR}}\left(\mathrm{E}_{\mathrm{s}}\right.$ in erg $)$ or $\log \left(\mathrm{E}_{\mathrm{s}}\right)=4.8+1.5 \mathrm{M}_{\mathrm{GR}}\left(\mathrm{E}_{\mathrm{s}}\right.$ in joule $)$ from the data with $\mathrm{M}_{\mathrm{GR}} \geq 5.5$.

Vanek et al.(1962) defined a new surface-wave magnitude, that is, $\mathrm{M}_{\mathrm{s}}=\log (\mathrm{A} / \mathrm{T})+1.66 \log (\Delta)+3.3 \cdot \mathrm{M}_{\mathrm{s}}$ measures the maximum ground vertical surface-wave amplitude, i.e., $\mathrm{A}_{\mathrm{V}}$, recorded at an epicentral distance of $\Delta=20-160^{\circ}$ and focal depth less than $50 \mathrm{~km}$ for the USGS and $\Delta=20-160^{\circ}$

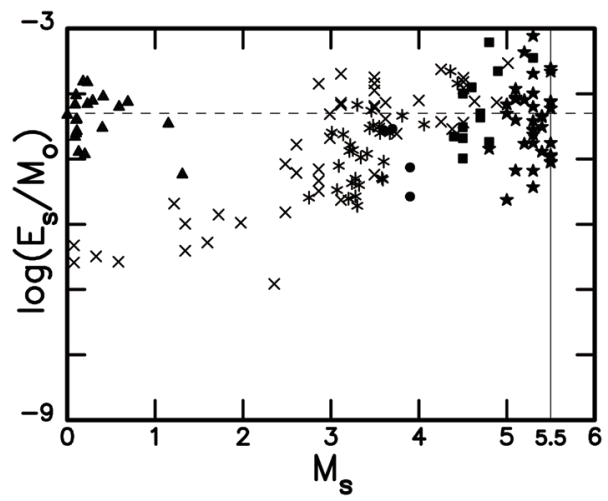

Fig. 7. The plot of $E_{\mathrm{s}} / M_{o}$ versus $M_{\mathrm{s}}$ : crosses for the data from Iio (1986), solid stars for those from Choy and Boatwright (1995); solid circles for those from Izutani and Kanamori (2001); solid triangles for those from Yamada et al. (2007); solid squares for those from Huang and Wang (2009), and asterisk for those from Sivaram et al. (2013). The thin vertical line represents $M_{\mathrm{s}}=5.5$. The thin horizontal dashed line represents $\mathrm{E}_{\mathrm{s}} / \mathrm{M}_{\mathrm{o}}=5.0 \times 10^{-5}$ (after Wang 2015). 
[for International Seismic Center (ISC)]. The wave period in use is $\mathrm{T}=18-22 \mathrm{sec}$. This formula is called the Prague formula and was suggested by International Association of Seismology and Physics of Earth's Interior (IASPEI) in 1967 to the working formula for measuring the surfacewave magnitude of an earthquake.

Can $\mathrm{M}_{\mathrm{GR}}$ be replaced by $\mathrm{M}_{\mathrm{s}}$ in the GR law? Abe (1981) found the equivalence of $\mathrm{M}_{\mathrm{s}}$ to $\mathrm{M}_{\mathrm{GR}}$ for global earthquakes. Lienkaemper (1984) observed that $\mathrm{M}_{\mathrm{s}}$ for the same events recomputed with the Prague formula is only 0.03 units of $\mathrm{M}_{\mathrm{s}}$ higher on average than $\mathrm{M}_{\mathrm{GR}}$. Wang and Miyamura (1990) and Wang (1992) found the similarity of the two magnitude scales for Taiwan's earthquakes. Based on the earthquake source spectra proposed by Aki (1967), the wave amplitudes with $\mathrm{T}=18-22 \mathrm{sec}$ are almost the same as those with $\mathrm{T}=17-23 \mathrm{sec}$. Consequently, $\mathrm{M}_{\mathrm{GR}}$ can be replaced by $\mathrm{M}_{\mathrm{s}}$ in the GR law.

The scaling exponent of the GR law is 1.5 . Theoretically, seismic radiation energy generated from a dynamic crack with an area of $\mathrm{A}$ is $\mathrm{E}_{\mathrm{s}}=\Delta \sigma \mathrm{DA} / 2$, where $\Delta \sigma$ and $\mathrm{D}$ are, respectively, the static stress drop and average slip on the crack plane, when the stress fully drops and the fracture energy can be negligible. This leads to $\mathrm{E}_{\mathrm{s}}=\Delta \sigma \mathrm{M}_{\mathrm{o}} / 2 \mu$ and thus $\log \left(\mathrm{E}_{\mathrm{s}}\right)=\log (\Delta \sigma / 2 \mu)+\log \left(\mathrm{M}_{\mathrm{o}}\right)$ where $\mathrm{M}_{\mathrm{o}}=\mu \mathrm{DA}$ is the seismic moment (Aki 1966; Aki and Richards 1980). Purcaru and Berckhemer (1978) obtained a scaling relationship between $\mathrm{M}_{\mathrm{o}}$ and $\mathrm{M}_{\mathrm{s}}$, i.e., $\log \left(\mathrm{M}_{\mathrm{o}}\right)=1.5 \mathrm{M}_{\mathrm{s}}+16.1\left(\mathrm{M}_{\mathrm{o}}\right.$ in dyne $\cdot \mathrm{cm})$. This yields $\log \left(\mathrm{E}_{\mathrm{s}}\right)=11.8+1.5 \mathrm{M}_{\mathrm{s}}$ under $\Delta \sigma / 2 \mu$ $=5.0 \times 10^{-5}$ which is a common value for most earthquakes (Knopoff 1958; Kanamori 1977). It is obvious that the $\mathrm{E}_{\mathrm{s}}$ $\mathrm{M}_{\mathrm{s}}$ relationship obtained from the dynamic crack model, together with an empirical relationship between $\mathrm{M}_{\mathrm{o}}$ and $\mathrm{M}_{\mathrm{s}}$, is the same as the GR law. This is the physical basis for making the GR law valid.

Since Gutenberg and Richter (1956) presented the GR law, numerous $\mathrm{E}_{\mathrm{s}}-\mathrm{M}_{\mathrm{s}}$ relationships have been inferred by various authors from different data sets. Some examples are given below. From teleseismic data, there $\operatorname{are} \log \left(\mathrm{E}_{\mathrm{s}}\right)=$ $7.75+1.87 \mathrm{M}_{\mathrm{GR}}$ by Tocher (1958); $\log \left(\mathrm{E}_{\mathrm{s}}\right)=7.2+2 \mathrm{M}_{\mathrm{GR}}$ by Bath and Duda (1964); and $\log \left(\mathrm{E}_{\mathrm{s}}\right)=7.5+2 \mathrm{M}_{\mathrm{GR}}$ by Reid et al. (cf. Fiedler 1967). From strong-motion seismograms, Vassiliou and Kanamori (1982) obtained $\log \left(\mathrm{E}_{\mathrm{s}}\right)=(9.06 \pm$ $1.38)+(1.81 \pm 0.20) \mathrm{M}_{\mathrm{s}}\left(\mathrm{M}_{\mathrm{s}} \geq 5.9\right)$. From the strong-motion seismograms recorded by the SMART- 1 array generated by 21 near-earthquakes $\left(\mathrm{M}_{\mathrm{s}}=4.1-7.8\right)$ with focal depths from $1-98 \mathrm{~km}$, Bolt and Wen (1990) measured the $\mathrm{E}_{\mathrm{s}}$ values of those events using the integral of the square of the ground velocity. The measured values are $E_{s}=8.612 \times 10^{18}-1.183$ $\times 10^{23} \mathrm{~g} \cdot \mathrm{cm}^{2} \mathrm{sec}^{-2}$. They inferred a relationship between $E_{s}$ and $\mathrm{M}_{\mathrm{s}}: \log \left(\mathrm{E}_{\mathrm{s}}\right)=(14.71 \pm 1.06)+(1.12 \pm 0.19) \mathrm{M}_{\mathrm{s}}$. PérezCampos and Beroza (2001) inferred numerous $\mathrm{E}_{\mathrm{s}}-\log \left(\mathrm{M}_{\mathrm{o}}\right)$ relationships. Obviously, these relationships are in general different from the GR law and the $\mathrm{E}_{\mathrm{s}}$ value calculated from their formula is higher than that from the GR law when $\mathrm{M}_{\mathrm{s}}$
$<7.7$. This might be due to over-estimates of $\mathrm{E}_{\mathrm{s}}$ by them, because the site effect was not removed from their measures, especially for strong-motion data. In addition, Kikuchi and Fukao (1988) observed that the $\mathrm{E}_{\mathrm{s}}$ values of thirty-five $M_{s}>6$ earthquakes are smaller than those calculated from the GR law

Choy and Boatwright (1995) compiled a data set of 397 global events with $M_{s}>4.4$. For the events with $M_{s}$ $>$ 5.7, they inferred an $\mathrm{E}_{\mathrm{s}}-\mathrm{M}_{\mathrm{s}}$ relationship: $\log \left(\mathrm{E}_{\mathrm{s}}\right)=11.4+$ $1.5 \mathrm{M}_{\mathrm{s}}$ (in ergs) or $\log \left(\mathrm{E}_{\mathrm{s}}\right)=4.4+1.5 \mathrm{M}_{\mathrm{s}}$ (in $\mathrm{J}$ ). This $\mathrm{E}_{\mathrm{s}}-\mathrm{M}_{\mathrm{s}}$ relationship is slightly different from the GR law. They also assumed that the GR law slightly over-estimates $\mathrm{E}_{\mathrm{s}}$. Nevertheless, the scaling exponents of the two laws are both 1.5.

Only the earthquakes with $\mathrm{M}_{\mathrm{s}}>5.5$ were taken by Gutenberg and Richter (1956) and Choy and Boatwright (1995) to infer the $E_{s}-M_{s}$ scaling law. Hence, in principle the GR law can be applied to evaluate $\mathrm{E}_{\mathrm{s}}$ only for $\mathrm{M}_{\mathrm{s}}>5.5$ earthquakes. However, the GR law has also been applied to evaluate $E_{s}$ even for small earthquakes for a long time. Naturally, a question appears: Can the law be applied to evaluate $E_{s}$ for micro- and small events with $0 \leq M_{s} \leq 5.5$ ?

In order to answer this question, the $\mathrm{E}_{\mathrm{s}}-\mathrm{M}_{\mathrm{s}}$ relationship for earthquakes with $M_{s} \leq 5.5$ must be studied from related $E_{s}$ and $\mathrm{M}_{\mathrm{s}}$ values for earthquakes with $\mathrm{M}_{\mathrm{s}} \leq 5.5$. Several groups of researchers (e.g., Iio 1986; Choy and Boatwright 1995; Izutani and Kanamori 2001; Yamada et al. 2007; Huang and Wang 2009; Sivaram et al. 2013) measured the $E_{\mathrm{s}}$ values for micro- and small earthquakes with $\mathrm{M}_{\mathrm{s}} \leq 5.5$ in different regions. One hundred sixty-six events, with $0.0 \leq \mathrm{M}_{\mathrm{s}} \leq 5.5$, $9.0 \times 10^{8} \mathrm{Nm} \leq \mathrm{M}_{\mathrm{o}} \leq 1.2 \times 10^{18} \mathrm{Nm}$, and $1.28 \times 10^{2} \mathrm{~J} \leq \mathrm{E}_{\mathrm{s}} \leq$ $3.30 \times 10^{14} \mathrm{~J}$, occurring in different regions were collected by Wang (2015) to study the problem. Except for the events with $0.5<\mathrm{M}_{\mathrm{s}}<1.5$ from Iio (1986), the data points of $\mathrm{E}_{\mathrm{s}}$ versus $\mathrm{M}_{\mathrm{s}}$ for earthquakes with $\mathrm{M}_{\mathrm{s}} \leq 5.5$ are almost around the GR law. This suggests that the seismic radiation energy of earthquakes with $M_{s} \leq 5.5$ can be evaluated from the GR law. Due to scattering of data points it is not easy to be sure if the GR law is better than the $\mathrm{E}_{\mathrm{s}}-\mathrm{M}_{\mathrm{s}}$ relationship inferred by Choy and Boatwright (1995) to interpret the observed data or not.

\section{SUMMARY}

Seismic radiation energy studies made pre-1999 are reviewed in this work. For those using the GR law to calculate $E_{s}$ the results should be corrected due to the use of non- $\mathrm{M}_{\mathrm{s}}$ earthquake magnitudes. The measure results for $\mathrm{E}_{\mathrm{s}}$ from strong-motion seismograms are questionable because the authors did not remove the FFBL and site effects. The theoretical studies on the FFBL effect by Wang (2004) and Wang and Huang (2007) and the site effect by Huang et al. $(2005,2007,2009)$ are described and discussed in this review article.

For the $\mathrm{M}_{\mathrm{s}} 7.6$ Chi-Chi earthquake of 20 September 1999, which ruptured the Chelungpu fault in Central Taiwan, 
Wang $(2004,2006 b)$ measured the strain energy $(\Delta E)$, seismic radiation energy $\left(E_{s}\right)$, fracture energy $\left(E_{g}\right)$, and frictional energy $\left(E_{f}\right)$ for the whole fault and its two segments. There are differences in the four kinds of energy between the northern and southern segments. Several important concluding points are given below:

(1) Wang (2004) obtained $\Delta \mathrm{E}=3.206 \times 10^{24} \mathrm{ergs}, \Delta \mathrm{E}_{\mathrm{N}}=$ $2.341 \times 10^{24} \mathrm{ergs}$, and $\Delta \mathrm{E}_{\mathrm{S}}=0.865 \times 10^{24} \mathrm{ergs}$, respectively, for the northern and southern segments, respectively.

(2) From near-field seismograms, Wang (2004) obtained $\mathrm{E}_{\mathrm{s}}=4.307 \times 10^{23} \mathrm{ergs}$ and $\mathrm{E}_{\mathrm{sN}}=3.981 \times 10^{23} \mathrm{ergs}$ for the northern segment and $\mathrm{E}_{\mathrm{sS}}=0.326 \times 10^{23} \mathrm{ergs}$ for the southern segments. The seismic efficiency, $\eta=E_{s} / \Delta E$, of the earthquake obtained from $\mathrm{E}_{\mathrm{s}}$ measured from nearfield seismograms and that from teleseismic data are, respectively, 0.137 and 0.262 , which do not agree with the $\eta \leq 0.06$ hypothesis proposed by McGarr (1994). On the other hand, based on the $\mathrm{E}_{\mathrm{S}}$ calculated from two $\mathrm{E}_{\mathrm{s}}-\mathrm{M}_{\mathrm{s}}$ laws, $\eta=0.049$ and 0.019 , which fit McGarr's hypothesis. However, the two laws could underestimate $E_{s}$. The radiation efficiency, i.e., $\eta_{R}=E_{s} /\left(E_{s}+E_{g}\right)$, are also evaluated.

(3) From local seismograms, Wang (2006b) obtained the optimum values: (1) $\mathrm{E}_{\mathrm{g}}=0.15 \times 10^{16} \mathrm{~J}, \eta_{\mathrm{R}}=0.69$, and $\mathrm{G}=0.33 \times 10^{7} \mathrm{~J} \mathrm{~m}^{-2}$ for the southern segment; and (2) $E_{g}=1.99 \times 10^{16} \mathrm{~J}, \eta_{\mathrm{R}}=0.67$, and $\mathrm{G}=5.34 \times 10^{7} \mathrm{~J} \mathrm{~m}^{-2}$ for the northern segment.

(4) For the frictional heat, $E_{f}$, caused by dynamic frictional stress, there is a marked difference between the two segments. The average frictional and ambient stress levels on the two segments are estimated. The total energy budget of and heat generated by the earthquake are elucidated based on a 2-D faulting model with frictional heat. Both observed and calculated results suggest the possible existence of fluids, which produced suprahydrostatic gradients, on the fault during faulting. Lubrication and thermal fluid pressurization might play a significant role on rupture.

(5) From the core samples obtained at Hole A of the TCDP, Wang (2011) evaluated the heat strength $\left(=7.0^{\circ} \mathrm{C} \mathrm{m}\right)$, within a heated layer of $\sim 5 \mathrm{~mm}$, due to frictional faulting from the values of shear stress and thermal and mechanical parameters. Based on a 1-D heat conduction equation and 2-D faulting model, with the values of thermal diffusivity evaluated within a representative temperature range, the thermal and pore fluid pressure history at depths $1110.37-1111.34 \mathrm{~m}$ in Hole-A is constructed. Results show that the peak temperature at the center of the heated layer could have been higher than $1100^{\circ} \mathrm{C}$ during faulting, and the temperature rise decreased quickly with increasing distance and time. This provides an answer to the so-called heat flux paradox (Lachenbruch and Sass 1980). There is no high thermal anomaly during faulting due to a remarkable decrease in the effective frictional stress.

(6) There are remarkable relationships between the temperatures and chemical reactions of clay minerals. In the heated layer, pseudotachylites have been formed and quartz plasticity might also have been operative during faulting. Outside this slip zone, the temperature rise was low and thus clay minerals were stable during faulting. The evaluated pore fluid pressure is $22.5 \mathrm{MPa}$, thus suggesting the existence of a suprahydrostatic state in the fault zone during the earthquake.

The radiation efficiency, $\eta_{R}$, is strongly affected by the variation in shear stress with slip. Wang (2009) considered thermal pressurization to be a significant mechanism in controlling such a variation, thus influencing $\eta_{R}$. He derived the formulae of $\eta_{\mathrm{R}}$ as a function of slip, $\delta$, on the basis of two end-member models of thermal pressurization, i.e., the AUD and SOP models, proposed by Rice (2006) are derived. The controlling parameters of the AUD and SOP models are, respectively, $\delta_{c}$ and $L^{*}$ which are individual in terms of the thermal, mechanical, and hydraulic parameters of fault rocks. Modeled results show that $\eta_{\mathrm{R}}$ increases with $\delta$. The increasing rate of $\eta_{\mathrm{R}}$ with $\delta$ is high at small $\delta$ and low at large $\delta$. This indicates that $\eta_{\mathrm{R}}$ varies very much with $\delta$ for small earthquakes and only slightly depends on $\delta$ for large events. For the two end-member models, $\eta_{\mathrm{R}}$ increases with decreasing $\delta_{\mathrm{c}}\left(\right.$ or $\left.\mathrm{L}^{*}\right)$. When $\delta_{\mathrm{c}}=\mathrm{L}^{*}, \eta_{\mathrm{R}}$ is higher for the AUD model than for the SOP model.

The correlation of the scaled energy, $e_{R}=E_{s} / M_{0}$, versus earthquake magnitude, $\mathrm{M}_{\mathrm{s}}$, is studied based on two models: (1) Model 1 based on the $\omega^{-2}$ source model; and (2) Model 2 based on the $\omega^{-3}$ source model. The results show that Model 1 influences the correlation of $e_{R}$ versus $M_{s}$; the source mod$\mathrm{el}$ is a factor, yet not a unique one, in controlling the correlation; and Model 2 cannot work for studying this correlation.

The scaling law of $E_{s}$ versus $M_{s}$, proposed by Gutenberg and Richter (1956) was originally based on $\mathrm{M}_{\mathrm{s}}>5.5$ earthquakes. Wang (2015) found that this law is also valid for earthquakes with $0<\mathrm{M}_{\mathrm{s}} \leq 5.5$. Meanwhile, the scaled energy is almost constant for $\mathrm{M}_{\mathrm{s}}>0$ earthquakes.

Acknowledgements I deeply thank a reviewer for her/his valuable comments to substantially improve the manuscript. This study was sponsored by Academia Sinica and Ministry of Science and Technology under Grand No. MOST 1042116-M-001-007.

\section{REFERENCES}

Abe, K., 1981: Magnitudes of large shallow earthquakes from 1904 to 1980. Phys. Earth Planet. Inter., 27, 7292, doi: 10.1016/0031-9201(81)90088-1. [Link]

Abercrombie, R. E., 1995: Earthquake source scaling relationships from -1 to $5 M_{L}$ using seismograms recorded 
at 2.5-km depth. J. Geophys. Res., 100, 24015-24036, doi: 10.1029/95JB02397. [Link]

Aki, K., 1966: Generation and propagation of $\mathrm{G}$ waves from the Niigata earthquake of June 16, 1964. Part 2. Estimation of earthquake moment, released energy, and stress-strain drop from the $\mathrm{G}$ wave spectrum. Bull. Earthq. Res. Inst., 44, 73-88.

Aki, K., 1967: Scaling law of seismic spectrum. J. Geophys. Res., 72, 1217-1231, doi: 10.1029/JZ072i004p01217. [Link]

Aki, K. and P. G. Richards, 1980: Quantitative Seismology, W. H. Freeman and Co., San Francisco, 932 pp.

Bath, M. and S. J. Duda, 1964: Earthquake volume, fault plane area, seismic energy, strain, deformation and related quantities. Ann. Geophys., 17, 353-368, doi: 10.4401/ag-5213. [Link]

Beresnev, I. A. and G. M. Atkinson, 1997: Modeling finitefault radiation from the $\omega^{n}$ spectrum. Bull. Seismol. Soc. Am., 87, 67-84.

Boatwright, J., 1978: Detailed spectral analysis of two small New York state earthquakes. Bull. Seismol. Soc. Am., 68, 1117-1131.

Boatwright, J., 1980: A spectral theory for circular seismic sources; simple estimates of source dimension, dynamic stress drop, and radiated seismic energy. Bull. Seismol. Soc. Am., 70, 1-27.

Boatwright, J. and J. B. Fletcher, 1984: The partition of radiated energy between $P$ and $S$ waves. Bull. Seismol. Soc. Am., 74, 361-376.

Bolt, B. A. and K. L. Wen, 1990: Seismic energy and intensity variability near the earthquake source from a strong motion array. In: Seed, H. B. (Ed.), Memorial Symposium Proceedings, Bitech Pub Ltd, Richmond, British Columbia, Canada, 1-16.

Boore, D. M., 1986: The effect of finite bandwidth on seismic scaling relationships. In: Das, S., J. Boatwright, and C. H. Scholz (Eds.), Earthquake Source Mechanics, Geophysical Monograph 37, American Geophysical Union, Washington, D.C., 275-283

Boore, D. M. and W. B. Joyner, 1997: Site amplifications for generic rock sites. Bull. Seismol. Soc. Am., 87, 327-341.

Brodsky, E. E. and H. Kanamori, 2001: Elastohydrodynamic lubrication of faults. J. Geophys. Res., 106, 1635716374, doi: 10.1029/2001JB000430. [Link]

Brune, J. N., 1970: Tectonic stress and the spectra of seismic shear waves from earthquakes. J. Geophys. Res., 75, 4997-5009, doi: 10.1029/JB075i026p04997. [Link]

Bullen, K. E., 1955: On the size of the strained region prior to an extreme earthquake. Bull. Seismol. Soc. Am., 45, 43-46.

Chang, Z. S. and T. C. Shin, 1994: Earthquakes in 1993. Meteorol. Bull., 39, 202-217. (in Chinese)

Chen, C. H., W. H. Wang, and T. L. Teng, 2001: 3D veloc- ity structure around the source area of the 1999 ChiChi, Taiwan, earthquake: Before and after the mainshock. Bull. Seismol. Soc. Am., 91, 1013-1027, doi: 10.1785/0120000737. [Link]

Chen, K. C. and J. H. Wang, 1985: The $b$-value distribution and seismicity maps of the Taiwan region. Proceedings of the ROC-JAPAN Joint Seminar Multiple Hazards Mitigation, National Taiwan University, Taipei, Taiwan, ROC, 69-82.

Choy, G. L. and J. L. Boatwright, 1995: Global patterns of radiated seismic energy and apparent stress. J. Geophys. Res., 100, 18205-18228, doi: 10.1029/95JB01969. [Link]

Dahlen, F. A., 1977: The balance of energy in earthquake faulting. Geophys. J. Int., 48, 239-261, doi: 10.1111/ j.1365-246X.1977.tb01298.x. [Link]

Di Bona, M. and A. Rovelli, 1988: Effects of the bandwidth limitation on stress drops estimated from integrals of the ground motion. Bull. Seismol. Soc. Am., 78, 1818-1825.

Dominguez, S., J. P. Avouac, and R. Michel, 2003: Horizontal coseismic deformation of the 1999 Chi-Chi earthquake measured from SPOT satellite images: Implications for the seismic cycle along the western foothills of central Taiwan. J. Geophys. Res., 108, doi: 10.1029/2001JB000951. [Link]

Eguchi, T. and S. Uyeda, 1983: Seismotectonics of the Okinawa trough and Ryukyu arc. Mem. Geol. Soc. China, 5, 189-210.

Favreau, P. and R. J. Archuleta, 2003: Direct seismic energy modeling and application to the 1979 Imperial Valley earthquake. Geophys. Res. Lett., 30, 1198, doi: 10.1029/2002GL015968. [Link]

Fialko, Y. A. and A. M. Rubin, 1997: Numerical simulation of high-pressure rock tensile fracture experiments: Evidence of an increase in fracture energy with pressure? J. Geophys. Res., 102, 5231-5242, doi: 10.1029/96JB03859. [Link]

Fiedler, G. E., 1967: Some notes on earthquake faults, magnitude and strain energy. Bull. Int. I. Seismol. Earthq. Eng., 4, 47-61.

Galitzin, M. B., 1915: Sur le tremblement de terre du 18 février 1911. Competes Rendus, 160, 810-814.

Gutenberg, B., 1945: Amplitudes of surface waves and magnitudes of shallow earthquakes. Bull. Seismol.Soc. Am., 35, 3-12.

Gutenberg, B. and C. F. Richter, 1942: Earthquake magnitude, intensity, energy, and acceleration. Bull. Seismol. Soc. Am., 32, 163-191.

Gutenberg, B. and C. F. Richter, 1956: Magnitude and energy of earthquake. Ann. Geofisica, 9, 1-15.

Haskell, N. A., 1966: Total energy and energy spectral density of elastic wave radiation from propagating faults. Part II. A statistical source model. Bull. Seismol. Soc. Am., 56, 125-140. 
Heaton, T. H., 1990: Evidence for and implications of selfhealing pulses of slip in earthquake rupture. Phys. Earth Planet. Inter ., 64, 1-20, doi: 10.1016/0031-9201(90)90002-F. [Link]

Hirono, T., T. Yokoyama, Y. Hamada, W. Tanikawa, T. Mishima, M. Ikehara, V. Famin, M. Tanimizu, W. Lin, W. Soh, and S. R. Song, 2007: A chemical kinetic approach to estimate dynamic shear stress during the 1999 Taiwan Chi-Chi earthquake. Geophys. Res. Lett., 34, L19308, doi: 10.1029/2007GL030743. [Link]

Hirono, T., K. Fujimoto, T. Yokoyama, Y. Hamada, W. Tanikawa, O. Tadai, T. Mishima, M. Tanimizu, W. Lin, W. Soh, and S. R. Song, 2008: Clay mineral reactions caused by frictional heating during an earthquake: An example from the Taiwan Chelungpu fault. Geophys. Res. Lett., 35, L16303, doi: 10.1029/2008GL034476. [Link]

Hsu, M. T., 1971: Seismicity of Taiwan and some related problems. Bull. Int. I. Seismol. Earthq. Eng., 8, 41160.

Hsu, M. T., 1973: Energy accounts of earthquakes in Taiwan. Meteorol. Bull., Central Weather Bureau, 19, 3952. (in Chinese)

Huang, M. W. and J. H. Wang, 2002: Scaling of displacement spectra of near-fault seismograms of the 1999 Chi-Chi, Taiwan, earthquake. Geophys. Res. Lett., 29, doi: 10.1029/2001GL014021. [Link]

Huang, M. W. and J. H. Wang, 2009: Scaled energies of $M_{L} \geq 5.1$ aftershocks of the 1999 Chi-Chi, Taiwan, earthquake measured from local seismograms. Terr. Atmos. Ocean. Sci., 20, 671-685, doi: 10.3319/ TAO.2008.10.13.01(T). [Link]

Huang, M. W., J. H. Wang, R. D. Hwang, and K. C. Chen, 2002: Estimates of source parameters of two large aftershocks of the 1999 Chi-Chi, Taiwan, earthquake in the Chia-Yi area. Terr. Atmos. Ocean. Sci., 13, 299-312.

Huang, M. W., J. H. Wang, H. H. Hsieh, K. L. Wen, and K. F. Ma, 2005: Frequency-dependent sites amplifications evaluated from well-logging data in central Taiwan. Geophys. Res. Lett., 32, L21302, doi: 10.1029/2005GL023527. [Link]

Huang, M. W., J. H. Wang, K. F. Ma, C. Y. Wang, J. H. Hung, and K. L. Wen, 2007: Frequency-dependent site amplifications with $f \geq 0.01 \mathrm{~Hz}$ evaluated from velocity and density models in Central Taiwan. Bull. Seismol. Soc. Am., 97, 624-637, doi: 10.1785/0120060139. [Link]

Huang, M. W., J. H. Wang, H. H. Hsieh, and K. L. Wen, 2009: High frequency site amplification evaluated from Borehole data in the Taipei Basin. J. Seismol., 13, 601-611, doi: 10.1007/s10950-009-9153-3. [Link]

Huang, W. G., J. H. Wang, B. S. Huang, K. C. Chen, T. M. Chang, R. D. Hwang, H. C. Chiu, and C. C. P. Tsai, 2001: Estimates of source parameters for the 1999
Chi-Chi, Taiwan, earthquake based on Brune's source model. Bull. Seismol. Soc. Am., 91, 1190-1198, doi: 10.1785/0120000730. [Link]

Hung, J. H., Y. H. Wu, E. C. Yeh, and TCDP Scientific Party, 2007: Subsurface structure, physical properties, and fault zone characteristics in the scientific drill holes of Taiwan Chelungpu-Fault Drilling Project. Terr. Atmos. Ocean. Sci., 18, 271-293, doi: 10.3319/ TAO.2007.18.2.271(TCDP). [Link]

Husseini, M. I., D. B. Jovanovich, M. J. Randall, and L. B. Freund, 1975: The fracture energy of earthquakes. Geophys. J. Int., 43, 367-385, doi: 10.1111/j.1365246X.1975.tb00640.x. [Link]

Hwang, R. D., 2012: Estimating the radiated seismic energy of the $2010 \mathrm{M}_{\mathrm{L}}$ 6.4 JiaSian, Taiwan, earthquake using multiple-event analysis. Terr. Atmos. Ocean. Sci., 23, 459-465, doi: 10.3319/TAO.2012.03.30.01(T). [Link]

Hwang, R. D., J. H. Wang, B. S. Huang, K. C. Chen, W. G. Huang, T. M. Chang, H. C. Chiu, and C. C. P. Tsai, 2001: Estimates of stress drop of the Chi-Chi, Taiwan, earthquake of 20 September 1999 from near-field seismograms. Bull. Seismol. Soc. Am., 91, 1158-1166, doi: 10.1785/0120000708. [Link]

Ide, S., 2002: Estimation of radiated energy of finite-source earthquake models. Bull. Seismol. Soc. Am., 92, 29943005, doi: 10.1785/0120020028. [Link]

Ide, S., 2003: Fracture surface energy of natural earthquakes from the viewpoint of seismic observations. Bull. Earthq. Res. Inst. Univ. Tokyo, 78, 59-65.

Ide, S. and G. C. Beroza, 2001: Does apparent stress vary with earthquake size? Geophys. Res. Lett., 28, 33493352, doi: 10.1029/2001GL013106. [Link]

Iio, Y., 1986: Scaling relation between earthquake size and duration of faulting for shallow earthquakes in seismic moment between $10^{10}$ and $10^{25}$ dyne $\cdot \mathrm{cm}$. J. Phys. Earth, 34, 127-169, doi: 10.4294/jpe1952.34.127. [Link]

Izutani, Y. and H. Kanamori, 2001: Scale-dependence of seismic energy-to-moment ratio for strike-slip earthquakes in Japan. Geophys. Res. Lett., 28, 4007-4010, doi: 10.1029/2001GL013402. [Link]

Jeffreys, H., 1923: The Pamir earthquake of 1911 February 18 , in relation to the depths of earthquake foci. Geophys. J. Int., 1, 22-31, doi: 10.1111/j.1365-246X.1923. tb06566.x. [Link]

Kanamori, H., 1977: The energy release in great earthquakes. J. Geophys. Res., 82, 2981-2987, doi: 10.1029/ JB082i020p02981. [Link]

Kanamori, H., 2004: The diversity of the physics of earthquakes. P. Jpn. Acad. B, 80, 297-316, doi: 10.2183/ pjab.80.297. [Link]

Kanamori, H. and T. H. Heaton, 2000: Microscopic and macroscopic physics of earthquakes. In: Rundle, J. B., D. L. Turcotte, and W. Klein (Eds.), Geocomplexity and the Physics of Earthquakes, American Geophysical Union, 
Washington, D. C., 147-163

Kanamori, H. and E. E. Brodsky, 2004: The physics of earthquakes. Rep. Prog. Phys., 67, 1429-1496, doi: 10.1088/0034-4885/67/8/R03. [Link]

Kanamori, H. and L. Rivera, 2004: Static and dynamic scaling relations for earthquakes and their implications for rupture speed and stress drop. Bull. Seismol. Soc. Am., 94, 314-319, doi: 10.1785/0120030159. [Link]

Kanamori, H., D. L. Anderson, and T. H. Heaton, 1998: Frictional melting during the rupture of the 1994 Bolivian earthquake. Science, 279, 839-842, doi: 10.1126/ science.279.5352.839. [Link]

Kano, Y., J. Mori, R. Fujio, H. Ito, T. Yanagidani, S. Nakao, and K. F. Ma, 2006: Heat signature on the Chelungpu fault associated with the 1999 Chi-Chi, Taiwan earthquake. Geophys. Res. Lett., 33, L14306, doi: 10.1029/2006GL026733. [Link]

Kikuchi, M., 1992: Strain drop and apparent strain for large earthquakes. Tectonophysics, 211, 107-113, doi: 10.1016/0040-1951(92)90054-A. [Link]

Kikuchi, M. and Y. Fukao, 1988: Seismic wave energy inferred from long-period body wave inversion. Bull. Seismol. Soc. Am., 78, 1707-1724.

Kinoshita, S. and M. Ohike, 2002: Scaling relations of earthquakes that occurred in the upper part of the Philippine Sea plate beneath the Kanto region, Japan, estimated by means of borehole recordings. Bull. Seismol. Soc. Am., 92, 611-624, doi: 10.1785/0120010134. [Link]

Knopoff, L., 1958: Energy release in earthquakes. Geophys. J. Int., 1, 44-52, doi: 10.1111/j.1365-246X.1958. tb00033.x. [Link]

Kostrov, B. V., 1974: Seismic moment and energy of earthquakes, and seismic flow of rock (translated to English). Izv. Earth Phys., 1, 23-40.

Lachenbruch, A. H. and J. H. Sass, 1980: Heat flow and energetics of the San Andreas Fault Zone. J. Geophys. Res., 85, 6185-6222, doi: 10.1029/JB085iB11p06185. [Link]

Lienkaemper, J. J., 1984: Comparison of two surface-wave magnitude scales: $M$ of Gutenberg and Richter (1954) and $M_{s}$ of "Preliminary determination of epicenters". Bull. Seismol. Soc. Am., 74, 2357-2378.

Lin, C. H., 2002: Active continental subduction and crustal exhumation: The Taiwan orogeny. Terr. Nova, 14, 281287, doi: 10.1046/j.1365-3121.2002.00421.x. [Link]

Ma, K. F., C. T. Lee, Y. B. Tsai, T. C. Shin, and J. Mori, 1999: The Chi-Chi, Taiwan earthquake: Large surface displacements on an inland thrust fault. Eos, Trans., $A G U$, 80, 605-611, doi: 10.1029/99EO00405. [Link]

Ma, K. F., T. R. A. Song, S. J. Lee, and H. I Wu, 2000: Spatial slip distribution of the September 20, 1999, Chi-Chi, Taiwan, earthquake $\left(\mathrm{M}_{\mathrm{w}} 7.6\right)$-- Inverted from teleseismic data. Geophys. Res. Lett., 27, 3417-3420, doi: 10.1029/2000GL011393. [Link]
Ma, K. F., J. Mori, S. J. Lee, and S. B. Yu, 2001: Spatial and temporal distribution of slip for the 1999 Chi-Chi, Taiwan, earthquake. Bull. Seismol. Soc. Am., 91, 10691087, doi: 10.1785/0120000728. [Link]

Ma, K. F., H. Tanaka, S. R. Song, C. Y. Wang, J. H. Hung, Y. B. Tsai, J. Mori, Y. F. Song, E. C. Yeh, W. Soh, H. Sone, L. W. Kuo, and H. Y. Wu, 2006: Slip zone and energetics of a large earthquake from the Taiwan Chelungpu-fault Drilling Project. Nature, 444, 473476, doi: 10.1038/nature05253. [Link]

Ma, S. and R. J. Archuleta, 2006: Radiated seismic energy based on dynamic rupture models of faulting. J. Geophys. Res., 111, B05315, doi: 10.1029/2005JB004055. [Link]

Marone, C., 1998: Laboratory-derived friction laws and their application to seismic faulting. Annu. Rev. Earth Planet. Sci., 26, 643-696, doi: 10.1146/annurev. earth.26.1.643. [Link]

McGarr, A., 1994: Some comparisons between mininginduced and laboratory earthquakes. Pure Appl. Geophys., 142, 467-489, doi: 10.1007/BF00876051. [Link]

McGarr, A., 1999: On relating apparent stress to the stress causing earthquake fault slip. J. Geophys. Res., 104, 3003-3011, doi: 10.1029/1998JB900083. [Link]

Mori, J., 2004: Energy budget of the 1999 Chichi, Taiwan earthquake. American Geophysical Union, Fall Meeting 2002, abstract \#S71E-09.

Otsuki, K., T. Uzuki, and Y. Koizumi, 2001: Presentation on core analysis. Proceed. ICDP Workshop on Drilling the Chelungpu Fault, Taiwan, Taipei, Vol. 37.

Pérez-Campos, X. and G. C. Beroza, 2001: An apparent mechanism dependence of radiated seismic energy. J. Geophys. Res., 106, 11127-11136, doi: 10.1029/2000JB900455. [Link]

Prejean, S. G. and W. L. Ellsworth, 2001: Observations of earthquake source parameters at $2 \mathrm{~km}$ depth in the Long Valley Caldera, Eastern California. Bull. Seismol. Soc. Am., 91, 165-177, doi: 10.1785/0120000079. [Link]

Purcaru, G. and H. Berckhemer, 1978: A magnitude scale for very large earthquakes. Tectonophysics, 49, 189198, doi: 10.1016/0040-1951(78)90177-4. [Link]

Rice, J. R., 2006: Heating and weakening of faults during earthquake slip. J. Geophys. Res., 111, B05311, doi: 10.1029/2005JB004006. [Link]

Rice, J. R., C. G. Sammis, and R. Parsons, 2005: Offfault secondary failure induced by a dynamic slip pulse. Bull. Seismol. Soc. Am., 95, 109-134, doi: 10.1785/0120030166. [Link]

Richter, C. F., 1935: An instrumental earthquake magnitude scale. Bull. Seismol. Soc. Am., 25, 1-32.

Rivera, L. and H. Kanamori, 2005: Representations of the radiated energy in earthquakes. Geophys. J.Int., 162, 148155, doi: 10.1111/j.1365-246X.2005.02648.x. [Link] 
Ruina, A., 1983: Slip instability and state variable friction laws. J. Geophys. Res., 88, 10359-10370, doi: 10.1029/ JB088iB12p10359. [Link]

Satoh, T., H. Kawase, T. Iwata, S. Higashi, T. Sato, K. Irikura, and H.C. Huang, 2001: S-wave velocity structure of the Taichung basin, Taiwan, estimated from array and single-station records of microtremors. Bull. Seismol. Soc. Am., 91, 1267-1282, doi: 10.1785/0120000706. [Link]

Savage, J. C. and M. D. Wood, 1971: The relation between apparent stress and stress drop. Bull.Seismol.Soc.Am., 61, 1381-1388.

Scholz, C. H., 1990: The Mechanics of Earthquakes and Faulting, Cambridge University Press, 461 pp.

Shin, T. C., 1993: The calculation of local magnitude from the simulated Wood-Anderson seismograms of the short-period seismograms in the Taiwan area. Terr. Atmos. Ocean. Sci., 4, 155-170.

Shin, T. C. and T. L. Teng, 2001: An overview of the 1999 Chi-Chi, Taiwan, earthquake. Bull. Seismol. Soc. Am., 91, 895-913, doi: 10.1785/0120000738. [Link]

Shin, T. C. and J. S. Chang, 2005: Earthquake monitoring systems in Taiwan. In: Wang, J. H. (Ed.), The 921 ChiChi Major Earthquake, Office of Inter-Ministry S\&T Program for Earthquake and Active-fault Research, NSC, 43-59. (in Chinese)

Sibson, R. H., 1992: Implications of fault-valve behaviour for rupture nucleation and recurrence. Tectonophysics, 211, 283-293, doi: 10.1016/0040-1951(92)90065-E. [Link]

Singh, S. K. and M. Ordaz, 1994: Seismic energy release in Mexican subduction zone earthquakes. Bull. Seismol. Soc. Am., 84, 1533-1550.

Sivaram, K., D. Kumar, S. S. Teotia, S. S. Rai, and K. S. Prakasam, 2013: Source parameters and scaling relations for small earthquakes in Kumaon Himalaya, India. J. Seismol., 17, 579-592, doi: 10.1007/s10950-012-9339-y. [Link]

Song, S. R., C. Y. Wang, J. H. Hung, and K. F. Ma, 2007a: Preface to the special issue on Taiwan ChelungpuFault Drilling Project (TCDP): Site characteristics and on-site measurements. Terr. Atmos. Ocean. Sci., 18 , I-VI, doi: 10.3319/TAO.2007.18.2.I(TCDP). [Link]

Song, S. R., L. W. Kuo, E. C. Yeh, C. Y. Wang, J. H. Hung, and K. F. Ma, 2007b: Characteristics of the lithology, fault-related rocks and fault zone structures in TCDP Hole-A. Terr. Atmos. Ocean. Sci., 18, 243-269, doi: 10.3319/TAO.2007.18.2.243(TCDP). [Link]

Spottiswoode, S. M. and A. McGarr, 1975: Source parameters of tremors in a deep-level gold mine. Bull. Seismol. Soc. Am., 65, 93-112.

Tanaka, H., C. Y. Wang, W. M. Chen, A. Sakaguchi, K. Ujiie, H. Ito, and M. Ando, 2002: Initial science report of shallow drilling penetrating into the Chelungpu fault zone, Taiwan. Terr. Atmos. Ocean. Sci., 13, 227-251.

Tanaka, H., W. M. Chen, C. Y. Wang, K. F. Ma, N. Urata, J. Mori, and M. Ando, 2006: Frictional heat from faulting of the 1999 Chi-Chi, Taiwan earthquake. Geophys. Res. Lett., 33, L16316, doi: 10.1029/2006GL026673. [Link]

Tanaka, H., W. M. Chen, K. Kawabata, and N. Urata, 2007: Thermal properties across the Chelungpu fault zone and evaluations of positive thermal anomaly on the slip zones: Are these residuals of heat from faulting? Geophys. Res. Lett., 34, L01309, doi: 10.1029/2006GL028153. [Link]

Tinti, E., P. Spudich, and M. Cocco, 2005: Earthquake fracture energy inferred from kinematic rupture models on extended faults. J. Geophys. Res., 110, B12303, doi: 10.1029/2005JB003644. [Link]

Tocher, D., 1958: Earthquake energy and ground breakage. Bull. Seismol. Soc. Am., 48, 147-153.

Tsai, Y. B., T. L. Teng, J. M. Chiu, and H. L. Liu, 1977: Tectonic implications of the seismicity in the Taiwan region. Mem. Geol. Soc. China, 2, 13-41.

Turcotte, D. L. and G. Schubert, 1982: Geodynamics: Application of Continuum Physics to Geological Problems, Wiley, $464 \mathrm{pp}$.

Vanek, J. , A. Zatopek, V. Karnik, N. V. Kondorskaya, Y. V. Riznichenko, E. F. Savarensky, S. L. Solov'ev, and N. V. Shebalin, 1962: Standardization of magnitude scales. Bull. Acad. Sci. USSR, Geophys. Ser., 2, 108-111.

Vassiliou, M. S. and H. Kanamori, 1982: The energy release in earthquakes. Bull. Seismol. Soc. Am., 72, 371-387.

Venkataraman, A. and H. Kanamori, 2004: Observational constraints on the fracture energy of subduction zone earthquakes. J. Geophys. Res., 109, B05302, 1-20, doi: 10.1029/2003JB002549. [Link]

Wang, C. Y. and T. C. Shin, 1998: Illustrating 100 years of Taiwan seismicity. Terr. Atmos. Ocean. Sci., 9, 589-614.

Wang, J. H., 1988: $b$ values of shallow earthquakes in Taiwan. Bull. Seismol. Soc. Am., 78, 1243-1254.

Wang, J. H., 1989: The Taiwan Telemetered Seismographic Network. Phys. Earth Planet. Inter., 58, 9-18, doi: 10.1016/0031-9201(89)90090-3. [Link]

Wang, J. H., 1992: Magnitude scales and their relations for Taiwan earthquakes: A review. Terr. Atmos. Ocean. Sci., 3, 449-468.

Wang, J. H., 1998: Studies of earthquake seismology in Taiwan during the 1897-1996 period. J. Geol. Soc. China, 41, 291-336.

Wang, J. H., 2002: A dynamic study of two one-statevariable, rate-dependent, and state-dependent friction laws. Bull. Seismol. Soc. Am., 92, 687-694, doi: 10.1785/0119980154. [Link]

Wang, J. H., 2004: The seismic efficiency of the 1999 ChiChi, Taiwan, earthquake. Geophys. Res. Lett., 31, 
L10613, doi: 10.1029/2004GL019417. [Link]

Wang, J. H., 2006a: A review of the source parameters of the $1999 \mathrm{M}_{\mathrm{s}}$ 7.6 Chi-Chi, Taiwan, earthquake. Terr. Atmos. Ocean. Sci., 17, 179-202.

Wang, J. H., 2006b: Energy release and heat generation during the $1999 \mathrm{M}_{\mathrm{s}} 7.6 \mathrm{Chi}-\mathrm{Chi}$, Taiwan, earthquake.J.Geophys. Res., 111, B11312, doi: 10.1029/2005JB004018. [Link]

Wang, J. H., 2009: Effect of thermal pressurization on radiation efficiency. Bull. Seismol. Soc. Am., 99, 22932304, doi: 10.1785/0120080187. [Link]

Wang,J.H., 2010: Summary of physical properties measured at several boreholes penetrating through the Chelungpu fault in central Taiwan. Terr. Atmos. Ocean. Sci., 21, 655-673, doi: 10.3319/TAO.2009.09.01.01(T). [Link]

Wang, J. H., 2011: Thermal and pore fluid pressure history on the Chelungpu fault at a depth of $1111 \mathrm{~m}$ during the 1999 Chi-Chi, Taiwan, earthquake. J. Geophys. Res., 116, B03302, doi: 10.1029/2010JB007765. [Link]

Wang, J. H., 2013: A theoretical study of correlation between scaled energy and earthquake magnitude based on two source displacement models. Earthq. Sci., 26, 373-376, doi: 10.1007/s11589-014-0068-x. [Link]

Wang, J. H., 2015: The energy-magnitude scaling law for $M_{s} \leq 5.5$ earthquakes. J. Seismol., 19, 647-652, doi: 10.1007/s 10950-014-9473-9. [Link]

Wang, J. H. and S. Miyamura, 1990: Comparison of several instrumentally-determined magnitude scales for Taiwan earthquakes (1900-1978). Proc. Geol. Soc. China, 33, 89-108.

Wang, J. H. and M. W. Huang, 2007: Effect of finite frequency bandwidth limitation on evaluations of seismic radiation energy of the 1999 Chi-Chi earthquake. Terr. Atmos. Ocean. Sci., 18, 567-576, doi: 10.3319/ TAO.2007.18.3.567(T). [Link]
Wang, J. H., M. W. Huang, K. C. Chen, R. D. Hwang, and W. Y. Chang, 2002: Aspects of characteristics of near-fault ground motions of the 1999 Chi-Chi (Taiwan) earthquake. J. Chin. Inst. Eng., 25, 507-519, doi: 10.1080/02533839.2002.9670726. [Link]

Wang, J. H., C. Y. Wang, Q. C. Song, T. C. Shin, S. B. Yu, C. F. Shieh, K. L. Wen, S. L. Chung, M. Lee, K. M. Kuo, and K. C. Chang, 2005: The 921 Chi- Chi Major Earthquake, Office of Inter-Ministry Science \& Technology Program for Earthquake and Active-fault Research, National Science Council, 582 pp. (in Chinese)

Wilson, B., T. Dewers, Z. Reches, and J. Brune, 2005: Particle size and energetics of gouge from earthquake rupture zones. Nature, 434, 749-752, doi: 10.1038/nature03433. [Link]

Wu, F. T., 1978: Recent tectonics of Taiwan. J. Phys. Earth, 26, S265-S299, doi: 10.4294/jpe1952.26.Supplement_ S265. [Link]

Wyss, M. and J. N. Brune, 1968: Seismic moment, stress, and source dimensions for earthquakes in the California-Nevada region. J. Geophys. Res., 73, 4681-4694, doi: 10.1029/JB073i014p04681. [Link]

Yamada, T., J. J. Mori, S. Ide, R. E. Abercrombie, H. Kawakata, M. Nakatani, Y. Iio, and H. Ogasawara, 2007: Stress drops and radiated seismic energies of microearthquakes in a South African gold mine. J. Geophy. Res., 112, B03305, doi: 10.1029/2006JB004553. [Link]

Yu, S. B., H. Y. Chen, and L. C. Kuo, 1997: Velocity field of GPS stations in the Taiwan area. Tectonophysics, 274, 41-59, doi: 10.1016/S0040-1951(96)00297-1. [Link]

Zhang, W., T. Iwata, K. Irikura, H. Sekiguchi, and M. Bouchon, 2003: Heterogeneous distribution of the dynamic source parameters of the 1999 Chi-Chi, Taiwan, earthquake. J. Geophys. Res., 108, doi: 10.1029/2002JB001889. [Link] 